\title{
A High Level of Transgenic Viral Small RNA Is Associated with Broad Potyvirus Resistance in Cucurbits
}

\author{
Diana Leibman, ${ }^{1}$ Dalia Wolf, ${ }^{2}$ Vinod Saharan, ${ }^{3}$ Aaron Zelcer, ${ }^{2}$ Tzahi Arazi, ${ }^{4}$ Shiboleth Yoel, ${ }^{1}$ \\ Victor Gaba, ${ }^{1}$ and Amit Gal-On ${ }^{1}$ \\ ${ }^{1}$ Department of Plant Pathology and Weed Science and ${ }^{2}$ Department of Vegetable Research, ARO The Volcani Center, Bet \\ Dagan 50250, Israel; ${ }^{3}$ Department of Molecular Biology and Biotechnology, Maharana Pratap University of Agriculture and \\ Technology, Udaipur-313001, Rajasthan, India; ${ }^{4}$ Department of Ornamental Horticulture, ARO The Volcani Center, Israel
}

Submitted 19 May 2011. Accepted 15 June 2011.

\begin{abstract}
Gene-silencing has been used to develop resistance against many plant viruses but little is known about the transgenic small-interfering RNA (t-siRNA) that confers this resistance. Transgenic cucumber and melon lines harboring a hairpin construct of the Zucchini yellow mosaic potyvirus (ZYMV) HC-Pro gene accumulated different levels of t-siRNA (6 to $44 \%$ of total siRNA) and exhibited resistance to systemic ZYMV infection. Resistance to Watermelon mosaic potyvirus and Papaya ring spot potyvirus-W was also observed in a cucumber line that accumulated high levels of t-siRNA (44\% of total siRNA) and displayed significantly increased levels of RNA-dependent RNA (RDR)1 and Argonaute 1, as compared with the other transgenic and nontransformed plants. The majority of the t-siRNA sequences were 21 to 22 nucleotides in length and sense strand biased. The t-siRNA were not uniformly distributed throughout the transgene but concentrated in "hot spots" in a pattern resembling that of the viral siRNA peaks observed in ZYMV-infected cucumber and melon. Mutations in ZYMV at the loci associated with the siRNA peaks did not break this resistance, indicating that hot spot t-siRNA may not be essential for resistance. This study shows that resistance based on genesilencing can be effective against related viruses and is probably correlated with t-siRNA accumulation and increased expression of RDR1.
\end{abstract}

RNA silencing or RNA interference is an evolutionarily conserved process that is found in a wide range of eukaryotic organisms and plays important roles in gene regulation and protecting the plant against viral attacks (Baulcombe 2004; Brodersen and Voinnet 2006; Waterhouse et al. 2001). Viral RNA silencing was first demonstrated by Lindbo and associates (1993), who showed that virus resistance in transgenic plants is associated with the degradation of transgenic RNA in the cytosol. A major mechanism of defense against viral invasion is a cascade of events called post-transcriptional gene silencing (PTGS), which leads to viral degradation induced by viral double-stranded (ds)RNA molecules (Ding and Voinnet 2007). It is likely that a mechanism similar to that used for the

We dedicate this paper to the memory of our dear colleague Aaron Zelcer, who died during the preparation of this manuscript.

Corresponding author: A. Gal-On; Telephone: +1 972-3-968-3563; Fax: +1 972-3-9683543; E-mail: amitg@volcani.agri.gov.il

* The $\boldsymbol{e}$-Xtra logo stands for "electronic extra" and indicates that a supplementary table is published online and Figure 3 appears in color online. recognition, targeting, and processing of viral RNA or endogenous dsRNA is also used for the processing of transgenic dsRNA (Fusaro et al. 2006).

The PTGS process occurs in several steps. First, endogenous and transgenic dsRNA molecules are cleaved into transgenic small-interfering (t-si)RNA duplex molecules by RNase IIIlike enzymes called DICERs (Dunoyer et al. 2010a). Plant DICERs (DCL4, DCL2, and DCL3) process the perfectly matched transgenic dsRNA into 21-, 22-, and 24-nucleotide (nt)-long duplex-siRNA fragments, respectively. All three DICERs function to some extent in the nucleus but DCL2 and DCL4 are more active in the cytosol (Bouche et al. 2006; Deleris et al. 2006; Ding and Voinnet 2007). Duplex siRNA has distinctive $3^{\prime}$ 2-nt overhangs which are methylated by HEN1 to a $2^{\prime}$-O-methyl group ( $\mathrm{Li}$ et al. 2005) while the $5^{\prime}$ recessed ends are phosphorylated (Xie et al. 2004).

The siRNA duplexes are then unwound. One strand is rapidly degraded and the other (the guide siRNA strand) is incorporated into the PAZ domain of the Argonaute 1 (AGO1) protein to form an RNA-induced silencing complex (RISC) (Aliyari and Ding 2009). Guide siRNA sequences associated with RISC complexes (activated RISC) base-pair with sites on target RNA molecules. In the case of t-siRNA, when a match is made between a guide t-siRNA and viral RNA, the activated RISC (RISC*) cleaves the viral RNA, causing its destruction.

dsRNA-mediated viral resistance in transgenic plants is based on the degradation of viral RNA only when there is (near-) perfect matching of the base pairs of the t-siRNA molecule with those of the viral genome. RISC* can potentially degrade any incoming single-stranded viral RNA based on sequence homology (Gaba et al. 2010; Prins et al. 2008). The structure of the microRNA duplex (miRNA/miRNA*) and the sequence at the $5^{\prime}$ end determine the miRNA guide strand in nematodes ( $\mathrm{Mi}$ et al. 2008). However, for endogenous plant siRNA, including t-siRNA, the guide strand preference within the siRNA duplex is not fully understood, although GC enrichment of viral siRNA (vsiRNA) has been reported for several RNA viruses (Donaire et al. 2009; Ho et al. 2007). A recent report proposed that vsiRNA populations have G-biases (Ho et al. 2010). vsiRNA and t-siRNA can also be produced via secondary amplification of dsRNA by RNA-dependent RNA (RDR) polymerases (RDR6 and RDR1) (Donaire et al. 2008; Garcia-Ruiz et al. 2010; Wang et al. 2010) primed with primary siRNA and associated proteins: SGS3 (Mourrain et al. 2000), the RNase D exonuclease WEX (Glazov et al. 2003), the siRNA-specific methyl-transferase HEN1 (Boutet et al. 2003), and the putative RNA helicase SDE3 (Dalmay et al. 2001). 
Over the last decade, transgenic virus resistance based on PTGS has been reported for several plant virus families in different host species. Many recent reports are based on the expression of a hairpin RNA transcript with a virus fragment inserted in opposite orientations (Waterhouse et al. 1998). This type of resistance is sequence dependent and, in some cases, strain specific (Bucher et al. 2006; Gaba et al. 2010; Savenkov and Valkonen 2002). In many cases, the level of RNA-based resistance is positively correlated with the accumulation of t-siRNA (Bucher et al. 2006; Chen et al. 2004; Kalantidis et al. 2002). PTGS-based viral resistance has been demonstrated for several Potyvirus spp. (Chen et al. 2004; Kreuze et al. 2008; Missiou et al. 2004; Vanderschuren et al. 2009), including those infecting cucurbits (Wu et al. 2009; Yu et al. 2010), even though Potyvirus spp. have a strong RNA-silencing suppressor, HC-Pro. It has been suggested that RISC* cleaves viral RNA before HC-Pro is produced and prevents the cell-to-cell movement of the virus (in the form of degraded viral RNA) before replication is initiated (Ding and Voinnet 2007).

Zucchini yellow mosaic virus (ZYMV), Papaya ring spot virus-W (PRSV-W), and Watermelon mosaic virus (WMV) are members of the genus Potyvirus, family Potyviridae, that cause devastating diseases in cucurbits all over the world. These viruses are positive single-stranded (ss)RNA viruses approximately 10,000 nt in length that are translated into polypeptides, which are processed into 9 to 10 proteins by viral proteases (Gal-On 2007). The second gene processed from the polyprotein is the multifunctional viral suppressor protein HC-Pro (Gal-On 2007). HC-Pro binds the vsiRNA duplex and miRNA in vitro and in vivo (Shiboleth et al. 2007). The sequestration of vsiRNA by HC-Pro (Shiboleth et al. 2007) and the reductions in the level of AGO1 protein induced by HC-Pro (Varallyay et al. 2010) may allow the Potyvirus sp. to compete with the plant's silencing mechanism. Potyvirus spp. produce small amounts of replicative form dsRNA, which are subjected to DCL-mediated cleavage, to yield a subset of primary vsiRNA (Garcia-Ruiz et al. 2010).

Levels of vsiRNA can increase independently of RDR polymerases via the dsRNA replicative form generated by the viral RNA polymerase complex (Ruiz-Ferrer and Voinnet 2009). The majority of vsiRNA is probably associated with aberrant RNA sequences (unprimed $5^{\prime}$ to $3^{\prime}$ ), following conversion of ssRNA fragments into dsRNA by the host RDR polymerases RDR1 and RDR6 (Garcia-Ruiz et al. 2010; Wang et al. 2010).

In the Arabidopsis rdrl mutant infected with Turnip mosaic potyvirus (TuMV), vsiRNA levels are significantly reduced, indicating the major role of RDR1 in vsiRNA biogenesis (Garcia-Ruiz et al. 2010). The association of resistance against RNA viruses with RDR1 has been shown to involve the salicylic acid pathway (Alamillo et al. 2006; Ji and Ding 2001; Xie et al. 2001; Yu et al. 2003). Moreover, transgenic silencing of RDR1 was shown to permit an increase in the level of the Potyvirus sp. Potato virus $Y$ (PVY) (Rakhshandehroo et al. 2009).

In this study, we characterize t-siRNA in transgenic cucumber and melon lines resistant to cucurbit Potyvirus spp. Using Illumina high-throughput sequencing and mutant viruses, we show that resistance to three Potyvirus spp. (ZYMV, WMV, and PRSV-W) depends on the level of expression of t-siRNA and an increase in the level of endogenous PTGS genes, especially RDR1. Characterization of t-siRNA revealed their asymmetrical distribution throughout the transgene. This pattern of distribution was similar to that of the vsiRNA in this region. Interestingly, hot spots of t-siRNA accumulation were not associated with virus resistance, as determined by examining a series of viruses with mutations in their respective transgenic regions.

\section{RESULTS}

Molecular characterization of an HC-Pro inverted repeat transgene in cucumber and melon.

We generated an inverted repeat construct harboring a 657nt fragment of the HC-Pro gene of ZYMV (Fig. 1A). The transgene was cloned in a hairpin configuration under the control of the $35 \mathrm{~S}$ promoter and the nos terminator (Fig. 1B). This binary vector, designated pART35S:ddHC-ZY, was used for Agrobacterium tumefaciens-mediated transformation of cucumber and melon. Selected transformed plants were used to study virus resistance and the traits of the t-siRNA. Two independent cucumber lines and two independent melon lines were used for analysis.

Transformed cucumber lines 823 and $887\left(\mathrm{~T}_{0}\right)$ were crosspollinated with nontransgenic, androgynous, open-pollinated cucumber 'Bet-Alpha' and the resulting kanamycin-resistant $\mathrm{T}_{1}$ seedlings (hemizygous) were self-pollinated. $\mathrm{T}_{2}$ seed progeny of line 823 (which segregated 1:3 for kanamycin resistance) were screened for kanamycin resistance to select homozygous $\mathrm{T}_{3}$ plants. Homozygous transgenic $\mathrm{T}_{3}$ plants of line 823 and hemizygous $T_{3}$ plants of line 887 were used in further experiments.

Transformed melon lines 177 and $443\left(\mathrm{~T}_{0}\right)$ were self-pollinated and kanamycin-resistant $T_{1}$ seedlings were self-pollinated twice. Line 443 segregated for kanamycin resistance at a rate of nearly 1:3 (21 of 33 transgenic) in the $\mathrm{T}_{3}$ generation; whereas 51 of 52 of the $T_{3}$ plants of line 177 were resistant to kanamycin.

Southern blot analyses were performed for cucumber line 823 and melon lines 177 and 443 (Fig. 1C). EcoRV was used to digest DNA of the transgenic lines, which was then hybridized with an HC-Pro-labeled fragment (657 nt). Southern blot analysis of the $T_{3}$ generation confirmed the integration of the HC-Pro fragment into the genomes of cucumber line 823 and melon lines 177 and 443 (Fig. 1C). In cucumber line 823 and melon line 443, two bands were observed (Fig. 1C). This may indicate the presence of two transgene copies per line, based on a unique EcoRV site within the nos promoter region (Fig. 1B). The two-band pattern was observed in each of the test plants of lines 823 and 443 (Fig. 1C), indicating that the two copies of the transgene are probably located near each other and segregate as one locus. The conclusion that the two inserts are located near each other on the same chromosome is reinforced by the 1:3 segregation rate for kanamycin resistance that was observed among the $T_{2}$ plants of both cucumber line 823 and melon line 443. A Southern blot analysis of melon plants from line 177 revealed a number of insertions ( 3 and 7 in different plants) (Fig. 1C), suggesting why 1 of $53 \mathrm{~T}_{3}$ plants was not transgenic.

Transgene expression was examined in the transformed cucumber (823 and 887) and melon (443 and 177) lines using reverse-transcription polymerase chain reaction (RT-PCR). Transcripts of transgenic RNA were detected only in transformed plants using specific primers corresponding to the transgene sequence (Fig. 1D). Based on the configuration of the hairpin construct, we expected that the intron would be cleaved out after transcription and that transgenic double-stranded (t-ds) RNA would be formed. The processing of this t-dsRNA into small RNA (t-siRNA fragments) by endogenous DICER-like proteins (DCL) was verified by Northern blotting (Fig. 1E) and deep sequencing (Fig. 2). Accumulation of 21- to 22-nt fragments of t-siRNA was observed in all of the transgenic lines but not in any of the healthy, nontransgenic plants $(\mathrm{H})$ (Figs. 1E and 2). The slight difference observed between ZYMV siRNA (ZY) and t-siRNA (Fig. 1E) is due to the preponderance of 22-nt fragments in the ZYMV-infected plants com- 
pared with the 21-nt fragments which were most common in transgenic plants. Northern blotting and deep sequencing revealed the accumulation of 24-nt t-siRNA fragments only in transgenic cucumber line 823 (Fig. 1E). The Northern blot showed that the level of t-siRNA in line 823 was 3.5 times that observed in the transgenic cucumber line 887 . However, deep sequencing revealed similar levels of t-siRNA in the transgenic melon lines 177 and 443 .

\section{t-siRNA sequence analysis.}

Sequencing analysis of total small RNA from transgenic cucumber and melon lines verified the accumulation of t-siRNA from the hairpin arms $(+\mathrm{HC}$ and $-\mathrm{HC})$ but not from the loop region (intron) (Fig. 1B). This indicates that only the transgenic dsRNA was processed into small RNA. In the homozygous cucumber line $823,43.5 \%$ of the total small RNA reads were generated from the transgene sequence, whereas the transgenic fraction of the total accumulated small RNA in line 887 was less than a third of this value $(12.7 \%)$ (Fig. 2A and B). In the transgenic melon lines 177 and 443, t-siRNA sequences accumulated to lower relative levels (5.7 and $7.9 \%$ of the total small RNA, respectively) (Fig. 2E and F). Interestingly, the levels of total small RNA observed in melon were two to three times higher than those observed in cucumber (Fig. 2), despite the fact that similar amounts of total RNA were used for deep sequencing. Compared with the t-siRNA, ZYMV

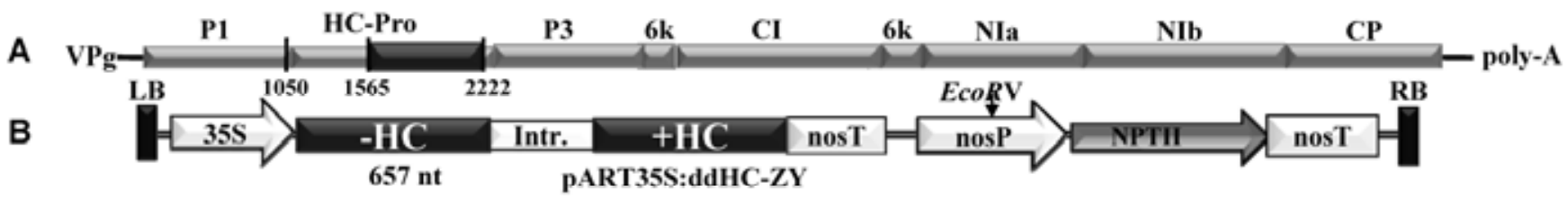

C

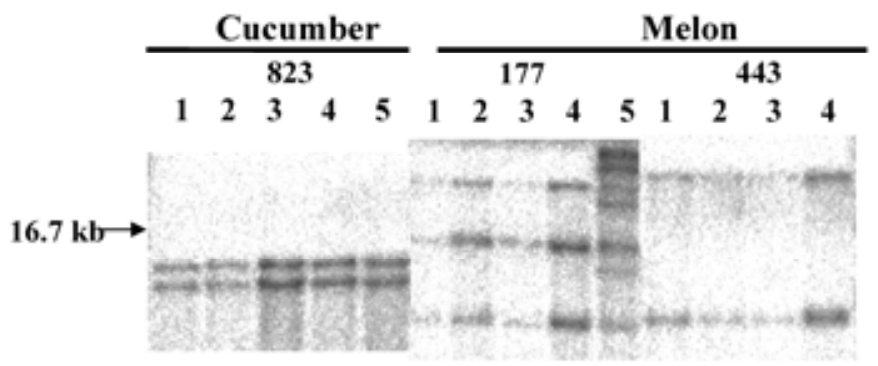

D

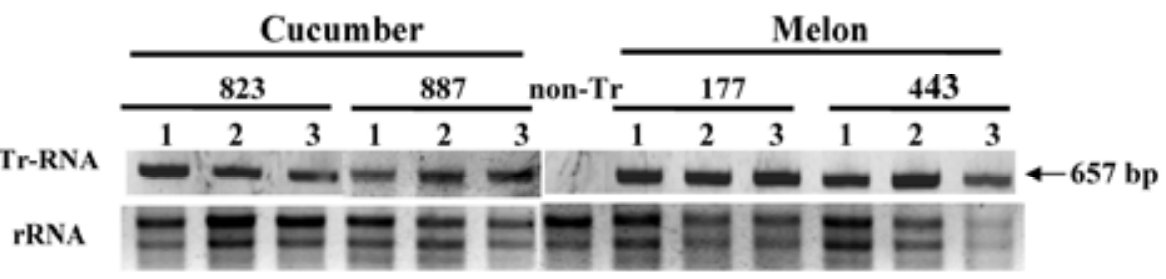

Cucumber

E

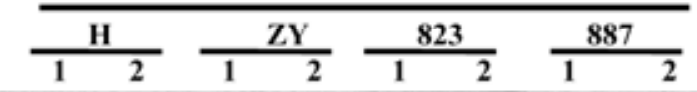

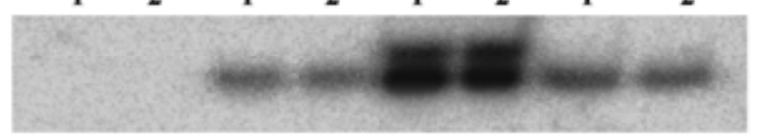

tRNA

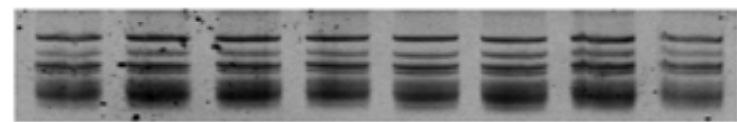

Melon

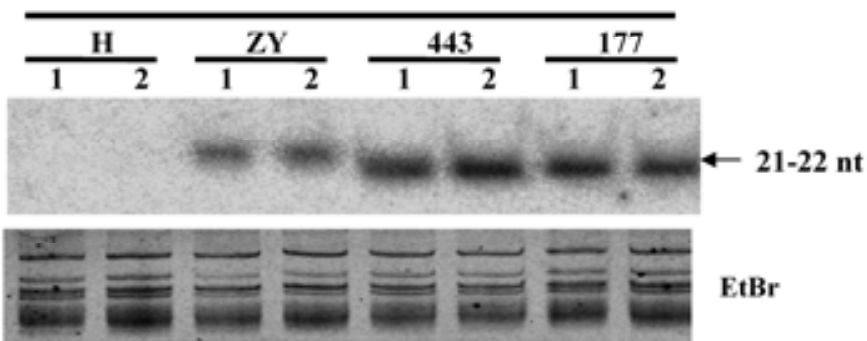

Fig. 1. Molecular characterization of transgenic cucumber and melon lines. A, Schematic representation of the Zucchini yellow mosaic virus (ZYMV) genome (Gal-On 2007). The HC-Pro region used for our transformations is marked by a black rectangle. B, T-DNA constructs used for plant transformation, with inserts between the left (LB) and the right (RB) borders. The T-DNA contains a sequence from the HC-Pro gene (657 nucleotides) in antisense (-HC) and sense $(+\mathrm{HC})$ orientations, on either side of the intron (Intr.), under the control of the $35 \mathrm{~S}$ promoter (35S) and the nos poly-A terminator (nosT), as well as the nptII selection gene (NPTII) under the control of the nos promoter (nosP). The EcoRV site used for the Southern blot is marked. C, Confirmation of the stable insertion of the transgene (HC-Pro fragment of $657 \mathrm{bp}$ ) in cucumber line 823 and melon lines 177 and 443 by Southern blot analysis. Aliquots $(20 \mu \mathrm{g}$ each) of EcoRV-digested DNA were separated on a $0.8 \%$ agarose gel and the blotted membrane was hybridized with a ${ }^{32} \mathrm{P}-\mathrm{labeled} \mathrm{HC}$-specific probe. Numbers 1 through 5 indicate individual transgenic $\mathrm{T}_{3}$ plants from each line. A molecular size marker (16.7 kbp) indicates the signal of the linear pART27:ddHC binary vector (not shown). D, Verification of expression of transgene RNA (Tr-RNA) in three different transgenic cucumber (lines 823 and 887 ) and melon (lines 177 and 443) plants (1, 2, and 3) and nontransgenic (nonTr) plants by reverse-transcription polymerase chain reaction (RT-PCR) analysis. RT-PCR was performed using total RNA (rRNA visualized by ethidium bromide (EtBr) staining) with primers homologous to the ends of the transgene and the amplified cDNA sequences were separated on a 1\% agarose gel. E, Northern blot analysis of the transgenic small-interfering (t-si)RNA that accumulated in the transgenic plants and the ZYMV siRNA that accumulated in the nontransgenic ZYMV-infected plants (ZY), at 7 days postinoculation, and uninoculated plants (H). Samples (10 $\mu \mathrm{g}$ each) of total RNA from transgenic cucumber (lines 823 and 887) and transgenic melon (lines 443 and 177 ). Two different plant samples (1 and 2) from each line were separated on a 15\% urea-polyacrylamide gel. The gel was stained with EtBr for RNA evaluation prior to transfer to nylon membrane. Membranes for cucumber and melon were hybridized with end-labeled ${ }^{32} \mathrm{P}$-primer mixture complementary to different regions of the HC-Pro transgene fragment. Nontransformed cucumber and melon plants $(\mathrm{H})$ served as negative controls. 
siRNA (vsiRNA) accounted for 27 and $25 \%$ of the total small RNA in infected, nontransgenic cucumber and melon plants, respectively. In comparison, vsiRNA reads referring to the transgene region (HC-Pro, $657 \mathrm{nt}$ ) accounted for only $2.3 \%$ of the total in both cucumber and melon (Fig. 2C and G).

\section{Characterization of ZYMV resistance in transgenic lines.}

Transgenic and nontransgenic cucumber and melon plants were sap inoculated with ZYMV at the cotyledon stage. All of the nontransformed plants began to display mosaic symptoms 7 to 8 days after infection (dpi). These initial symptoms developed into severe symptoms, including blisters, leaf deformation, and stunting, by $28 \mathrm{dpi}$ (Fig. 3; Table 1). In contrast, transgenic cucumber lines 823 (Fig. 3) and 887 (data not shown) did not exhibit any disease symptoms and displayed resistance to ZYMV systemic infection in three separate experiments (Table 1). Similar resistance was observed in transgenic melon lines 443 (Fig. 3) and 177 (data not shown), despite occasional resistance breaking in melon ( 1 of 37 tested plants of line 177 and of 2 of 32 plants of line 443) (Table 1).

Sequence analysis of the progeny virus from the resistancebreaking melon lines revealed no changes in the viral genome that corresponded to the 657-nt transgene sequence. The resistance of cucumber and melon lines to ZYMV infection was confirmed by RT-PCR at 7, 14, 21, and 28 dpi (Fig. 4A and B and data not shown). ZYMV RNA was successfully amplified from nontransformed cucumber and melon using RT-PCR but could not be amplified from any of the transgenic cucurbit

\section{Cucumber}
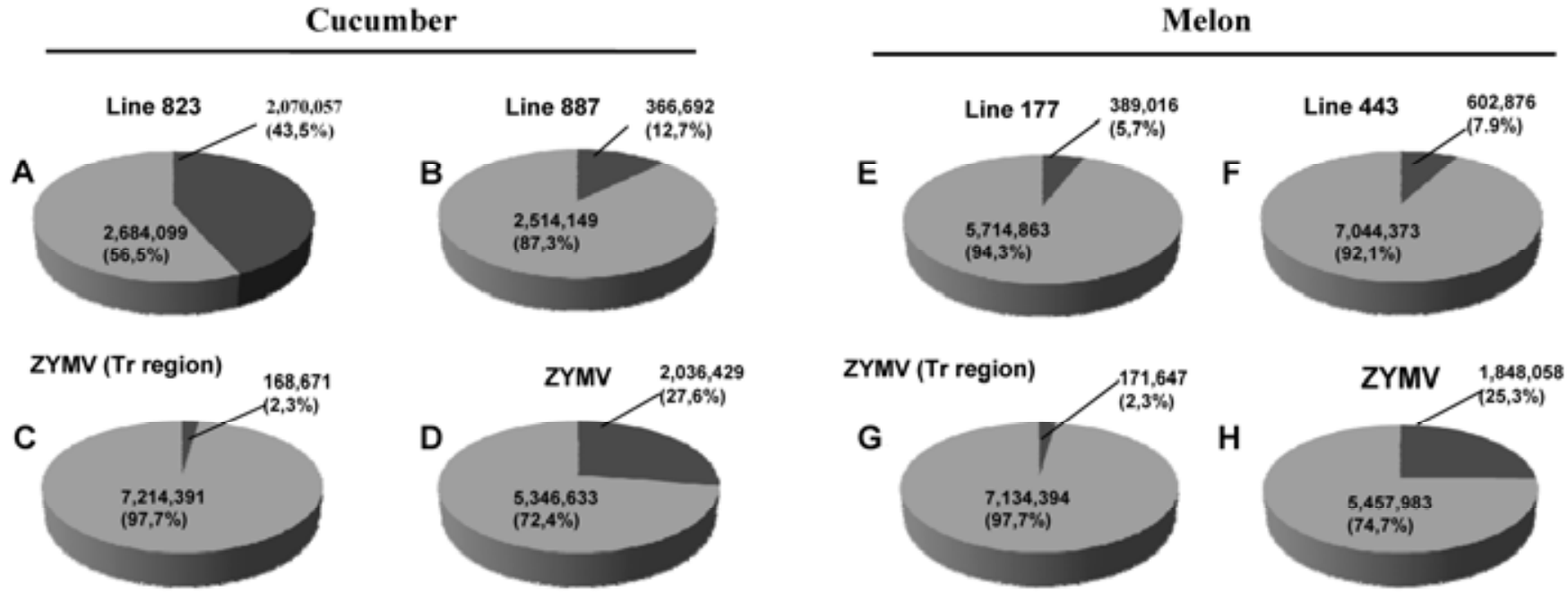

Fig. 2. Transgenic and viral small RNA reads captured from each of the six libraries of $\mathbf{A}$ and $\mathbf{B}$, transgenic cucumber; $\mathbf{E}$ and $\mathbf{F}$, transgenic melon; and Zucchini yellow mosaic virus (ZYMV)-infected nontransgenic $\mathbf{D}$, cucumber and $\mathbf{H}$, melon. Numbers and percentages of reads were from total. Endogenous small RNA reads are indicated by light-gray areas. Pie sections refer to transgenic small-interfering (t-si)RNA or ZYMV siRNA reads are marked in dark gray. Only ZYMV siRNA sequences that correspond to the transgene region (Tr-region) in ZYMV-infected nontransformed $\mathbf{C}$, cucumber and $\mathbf{G}$, melon are presented.
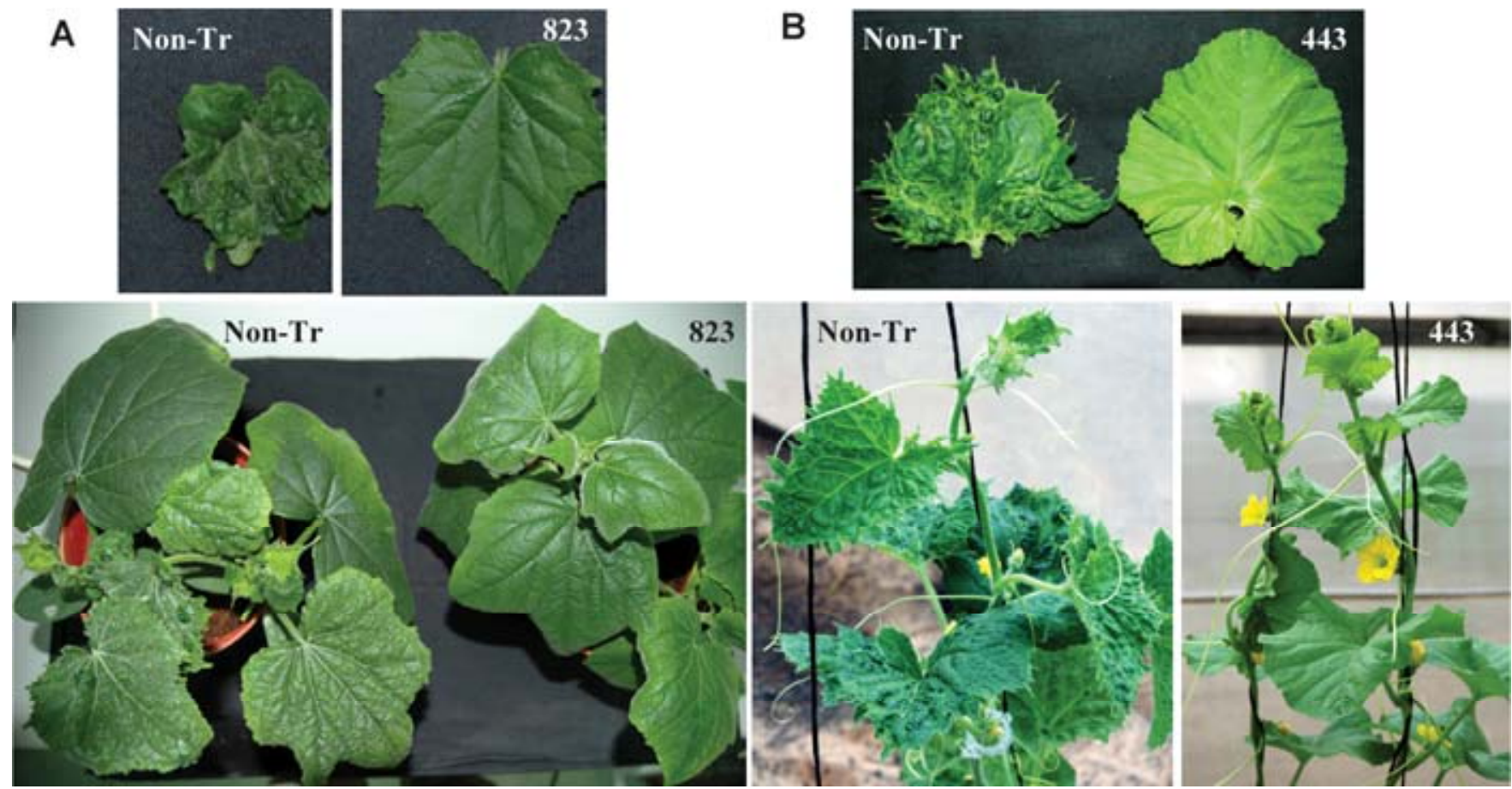

Fig. 3. Responses of A, nontransformed (non-Tr) cucumber and transgenic cucumber line 823 and $\mathbf{B}$, nontransformed melon and transgenic melon line 443 to mechanical inoculation with Zucchini yellow mosaic virus. Symptoms were observed at 14 days postinoculation (dpi) in cucumber and at 28 dpi in melon. 
lines when we attempted to do so at different time points after infection (including melon lines which were sometimes nonresistant). Representative data from cucumber line 823 at 7 and 28 dpi are shown in Figures 4A and 4B. (melon, data not shown). Infectious particles of ZYMV could not be recovered from the asymptomatic transgenic cucumber and melon plants, as determined by back inoculation of susceptible squash plants with extracts of the leaves of transgenic plants 3 weeks after the initial ZYMV inoculation.

\section{Resistance of the transgenic lines}

\section{to systemic infection by cucurbit Potyvirus spp.}

The transgene sequence of ZYMV HC-Pro (657 nt) exhibited 67 and $63 \%$ identity with the corresponding regions of the WMV and PRSV-W genomes, respectively (Fig. 5). Due to the relatively high level of homology between these cucurbit Potyvirus spp., we tested whether the transgenic cucumber and melon lines exhibited resistance to WMV and PRSV-W. As a negative control, we tested the resistance of the transgenic lines to the unrelated Cucumber mosaic cucumovirus (CMV). Cucumber (lines 823 and 887) and melon (lines 177 and 443) seedlings were mechanically inoculated with WMV and PRSV-W at the cotyledon stage and systemic virus infection was evaluated based on observations of symptoms and RTPCR at different time points following inoculation. Both transgenic cucumber lines ( 823 and 887 ) exhibited resistance to WMV and showed no signs of having been infected with this virus during the 4-week experiment (Table 2). However, although WMV could not be detected by RT-PCR in the homozygotic $\mathrm{T}_{3}$ plants of line 823 (Fig. 4C), in line 887 , a very low level of WMV viral RNA (0.3 to $0.03 \%$ of that of nontransformed plants) was detected by quantitative (Q)-RT-PCR (data not shown). Cucumber plants of the transgenic line 887 that were inoculated with PRSV-W exhibited severe foliar symptoms (mosaic with blisters) similar to those observed on the nontransformed cucumber plants. However, no symptoms were observed in cucumber line 823 (data not shown). Q-RTPCR analysis of the accumulation of PRSV-W RNA in systemically infected leaves of line 823 indicated a significantly lower level of virus accumulation than that observed in nontransformed cucumber (Fig. 4D).

To investigate whether the Potyvirus sp. resistance observed in cucumber line 823 may be due to a non-sequence-homology-dependent general resistance phenomena, we tested the resistance of this line to CMV infection. Typical CMV disease

Table 1. Response of transgenic cucumber and melon lines to mechanical inoculation with Zucchini yellow mosaic virus (ZYMV)

\begin{tabular}{lcccc}
\hline & \multicolumn{3}{c}{$\begin{array}{c}\text { Resistant plants/ } \\
\text { inoculated plants }^{\mathbf{a}}\end{array}$} & \\
\cline { 2 - 4 } Lines $^{\mathbf{b}}$ & $\mathbf{1}$ & $\mathbf{2}$ & $\mathbf{3}$ & Resistance (\%) \\
\hline Cucumber & & & & 100 \\
823 & $44 / 44$ & $17 / 17$ & $9 / 9$ & 100 \\
887 & $8 / 8$ & $4 / 4$ & $4 / 4$ & 0 \\
$\quad$ Nontransgenic & $0 / 15$ & $0 / 15$ & $0 / 13$ & 97 \\
Melon & & & & 94 \\
177 & $9 / 9$ & $12 / 13$ & $15 / 15$ & 0 \\
443 & $11 / 11$ & $9 / 11$ & $10 / 10$ & 0 \\
Nontransgenic & $0 / 10$ & $0 / 10$ & $0 / 11$ & \\
\hline
\end{tabular}

${ }^{a}$ Groups 1, 2, and 3 are three biological repeats.

$\mathrm{b}$ Transgenic and nontransgenic cucumber and melon plants were inoculated with ZYMV-NAT (accession number EF062582) and systemic infectivity was determined by the presence of symptoms 3 weeks postinfection.
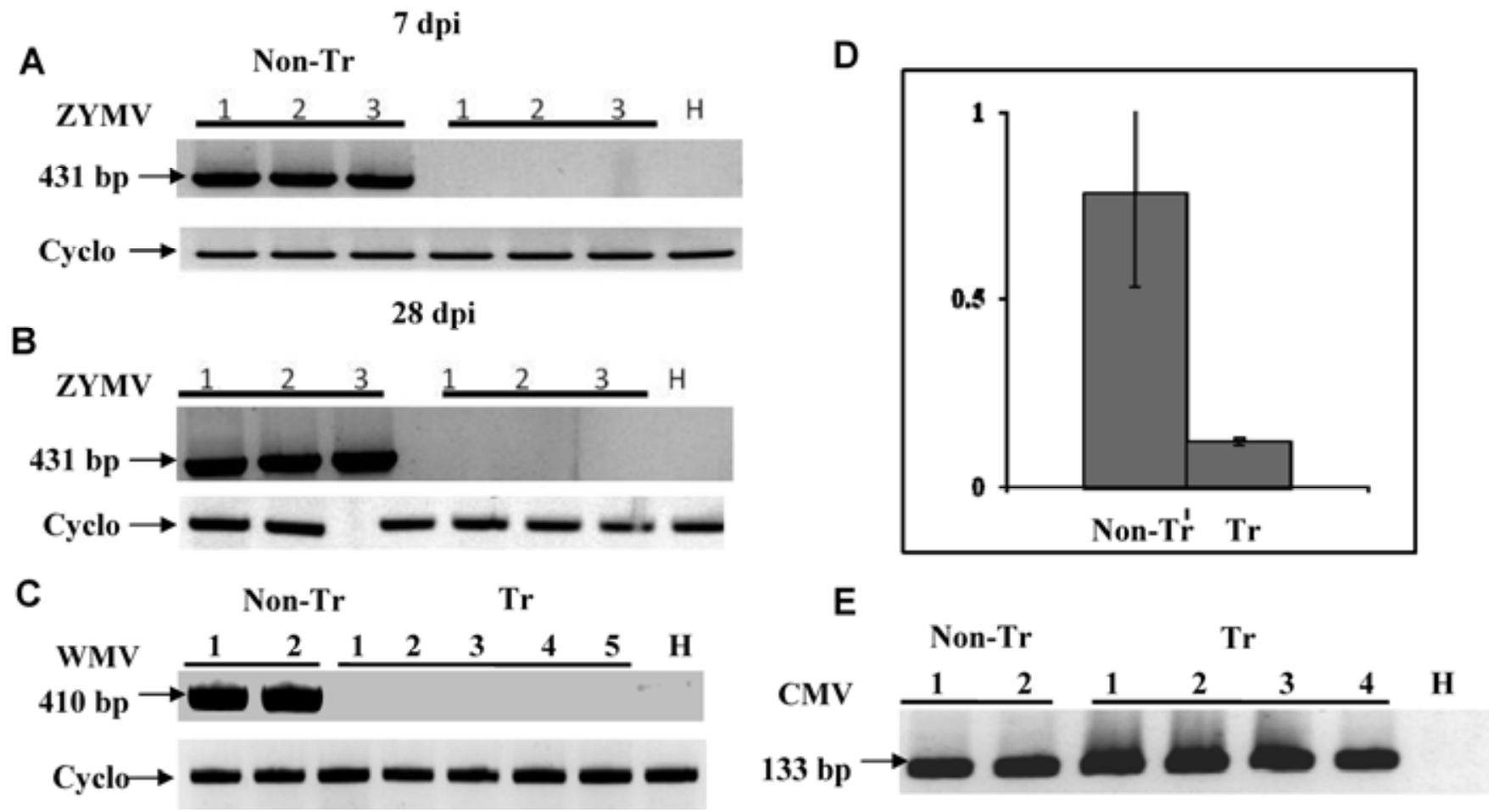

Fig. 4. Transgenic cucumber line 823 is resistant to systemic infection by potyviruses. Reverse-transcription polymerase chain reaction (RT-PCR) was carried out using total RNA extracted from transgenic (Tr) and nontransformed plants (non-Tr) that had been inoculated with Zucchini yellow mosaic virus (ZYMV) A, 7 days postinoculation (dpi) and B, 28 dpi; C, Watermelon mosaic virus (WMV) 14 dpi; D, Papaya ring spot virus-W (PRSV-W) 14 dpi; and E, Cucumber mosaic virus (CMV) 14 dpi. RT-PCR was performed using primers corresponding to the coat protein of each virus. The same RNA samples were used for RT-PCR of the cyclophilin gene (Cyclo) as reference control. An uninoculated plant (H) was used as a control. Samples of cDNA from different plants (numbers 1 to 5) were separated on a 1\% agarose gel and visualized by ethidium bromide staining. A cDNA size marker is shown on the left side of each gel. The accumulation of PRSV-W RNA (D) in transgenic and nontransgenic plants was compared by quantitative RT-PCR analysis of three biological repeats using cyclophilin as an internal control (data represent relative $\Delta \Delta$ cycle threshold values). 
symptoms and RNA accumulation were observed in both line 823 and the nontransformed control at 14 dpi (Fig. 4E). Systemic CMV infection was also observed in all the other transgenic cucurbit lines (Table 2). In contrast to the partial resistance to WMV and PRSV-W observed in the transgenic cucumber lines, no resistance to WMV and PRSV-W was observed in the transgenic melon lines (Table 2). Severe developmental symptoms, including leaf deformation and stunting, were observed in the transformed melon lines and the nontransformed control plants 2-3 weeks after infection (Table 2).

\section{Characterization of $t$-siRNA}

in transformed cucumber and melon.

To date, the significance of t-siRNA size and sequence in virus resistance has not been investigated in detail. To deepen our understanding of this topic, we sorted the t-siRNA reads (Figs. 6 and 7) according to size and sequence. t-siRNA sequences 21,22 , and $24 \mathrm{nt}$ in length were observed in sense and antisense polarities in transgenic cucumber (lines 823 and 887) and melon (lines 177 and 443) (Fig. 6). Higher numbers of $\mathrm{t}$-siRNA reads were counted for the sense as opposed to the antisense orientation in cucumber $(65 \%)$ and melon $(70 \%)$. t-siRNA reads $21 \mathrm{nt}$ in length made up the most common size class in both orientations, accounting for approximately $50 \%$ of the total small-RNA reads in cucumber and $60 \%$ of those in melon (Table 3). Sequence reads that were $22 \mathrm{nt}$ in length accounted for approximately 27 to $28 \%$ and 38 to $40 \%$ of the total t-siRNA in cucumber lines 823 and 887 , respectively (Table 3). Melon line 443 had more reads (33 to 36\%) in the $22-n t$ size class than line 177 (29 to $30 \%$ ) (Table 3). A relatively high percentage of 24-nt reads among the total t-siRNA reads $(18 \%)$ was observed only in cucumber line 823 (Table 3) (Fig. 2 ), and it is only in this line that the 24-nt class outnumbers the 20- or 23-nt t-siRNA.

The deep-sequencing data are supported by the results of the Northern blot hybridization (Fig. 1E; line 823). Interestingly, in ZYMV-infected, nontransformed cucumber and melon plants, a higher fraction of ZYMV-siRNA reads was observed
A

2nV-HC-Pr Warv-HC-Pro ZYMV-HC-P WMV-HC-PrO

ZYMV-HC-Pr hav-BC-Pro

$2 \mathrm{MV}-\mathrm{BC}-\mathrm{P} x$ WAN-HC-Pro

2MN-HC-Pr WoN-HC-Pro

ZYMV-HC-Pr Worv-BC-Pro

ZYMV-HC-Pr WMV-BC-Pro

B

$2 \mathrm{MV}-\mathrm{HC}-\mathrm{Pr}$ PRSV-HC-Pr

$\mathrm{ZMNV}-\mathrm{HC}-\mathrm{Pr}$ PRSV-BC-Pr

$\mathrm{ZYMV}-\mathrm{HC}-\mathrm{Pr}$ PRSV-HC-Px

ZMM-HCPRSV-HC-P ZYMV-BC-Pr PRSV-BC-P ZMN-HCPRSV-HC-Px

P2

P3

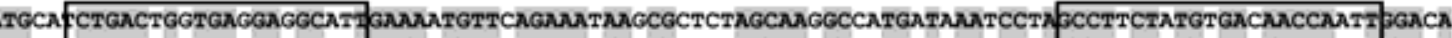
atgACECTGACCGATGAAGATGCGCD, GAAAGTGTTTAgaAACAAACGTAGCAGCAAAGCGCTGCTGAACCCGA GCCTGCTGTGCGATAACCAGCT

P6

AAATGGAAATTTGTTTGGGAGAAAGAGGATACCATTCCAAGCGATTATTCAAGAACTTCTTCGAAGAGTAATACCAAGCG AAGGATATACGAAGTA AAAACGGCAACTTTGTGTGGGGCGAACGTGGCAAACATAGCAAACGTTTTTTTGCGAACTATTTTGAAGAAGTGATTCCGAGCGAGGCTATAGCAAATA

CGTAG GCGAAACTTTCCAAATGGTACTCGRAATTGGCCATAGGCTCATTGATTGTACCACTCAATTTGGATAGGGCACGCACTGCACTACTTGGAGÄG PGTGA TCGTAAAAACCCGAACGGCCAGCGTGAACTEGCGATTGGCAGCCTGATTGTGCCGCTGGATTTTGAACGTGCGCGTATGGCGCTGCAGGGCAAA

P1

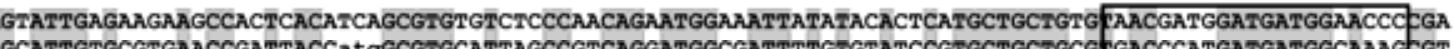

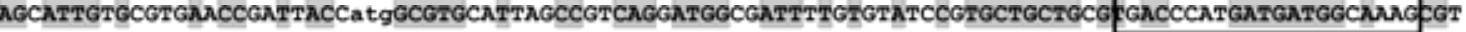

P5

P7

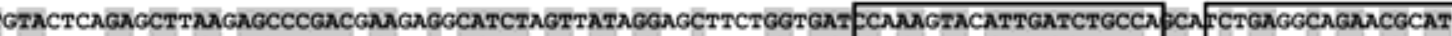
TTPATAGCGAACTGAAAAGCCCGACCAAACGTCATCTGGTGATTGGCACCAGCGGCGAT ECGAAATATATTGATCTGCCGPCG CCGAAACCGATCGT at

P4

GTATAT GCANAAGAAGGTTATTGCTATCTCAATATTTTCCTCGCAATGCTTGTGAATG FTAATGAGAACGAAGCAAAGG TTTCACCAAAATGATTCGT gTATAT FGGAAAGAAGGCTATTGCTATCTGAACATTTTTCTGGCGatgCTGGTGAACGEGAACGAAGATGAAGCGAAAGATTTTACCAAAATgGTGCGT

GATGTTTTGATCCCCATGCTTGGGCAGTGGC

GATGTGATTGTGCCGAAACTGGGCCAGTGEC

P2

P3

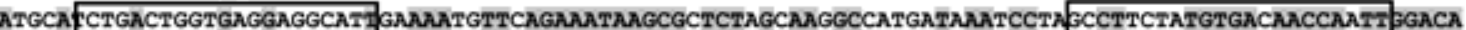
ACAGA TCAATAAARGCTGGCAGCGITGAAAGTTTAGANATAGCGTTCTGGAAAAGCTCATTTCAACCCA ETCTCACGTGTGATAACCAGTI SGACA

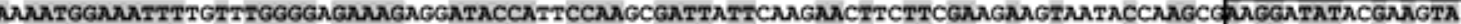

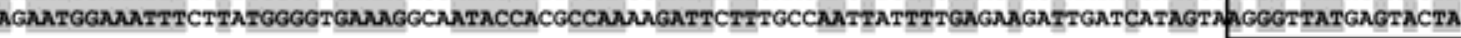

GTAG GCGAAACTTTCCAAATGGTACTCGTAAGTTGGCCATAGGCTCATTGATTGTACCACTCAATTTGGATAGGGCACGCACTGCACTACTTGGAGAG FAGTCAACGCCAAAACCCAAATGGTATCAGGAAAATCGCCATTGGCAATTTAGTATTTTCAACGAATTTGGAGGGATTTCGGCAGCAAATGGTCGAACAC

P1

GTATTGAGAAGAAGCCACTCACATCAGCGTGTGTCTCCCAACAGAATGGAAATTATATACACTCATGCTGCTGTG PAACGATGGATGATGGAACCCEGA CACATCGATCAAGGACCAATTACTCGTGAGTGCATTGCATTGCGCAATAACAATTATGTTCATGTGTGTAGCTGCG PAACTTTAGATGACGGAACTC CAG

P5

P7

GTACTCAGAGCTTAAGÄGCCCGACGAAGAGGCATCTAGTTATAGGAGCTTCTGGTGAT CCAAAGTACATTGATCTGCCA PCA PCTGAGGCAGAACGCAT CAACTAGTGAGTTGAAAACTCCTACCAAGAATCACATAGTTCTTGGTAATTCTGGTGAT ECTAAGTACGTTGACCTGCCGPCT ETTGAATCTGATTCGAT

P4

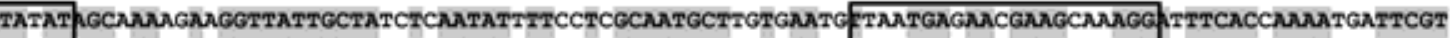

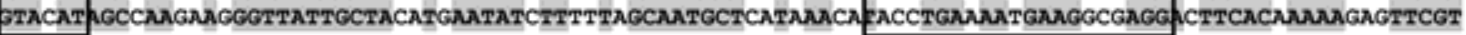

ZYMV-HC-Px GATGTTTTGATCCCCATGCTTGGGCÄGTGGC

PRSV-HC-PI GATCTTGTAGGTTCANACTTGGAGAMTGGC

Fig. 5. Sequence alignment of the transgenic HC-Pro segment (Zucchini yellow mosaic virus [ZYMV]-HC) with its homologues from A, Watermelon mosaic virus (WMV) and B, Papaya ring spot virus-W (PRSV-W). Identical nucleotides are shaded. Black rectangles indicate the positions of 21 nucleotides of transgenic small-interfering (t-si)RNA peaks, as determined by siRNA sequencing. 
in the sense orientation, similar to the distribution of t-siRNA in transgenic plants. Notably, the 22-nt class accounted for a majority of the vsiRNA (approximately 65 to 68\%) at 5 dpi (Fig. 6C and F).

\section{Frequency and distribution of nucleotides in t-siRNA.}

It has been shown that the nucleotide order within the siRNA has some specificity with argonaute complexes, as in miRNAs, especially at the 5' end (Mi et al. 2008). To study such specificity within t-siRNA sequences (21 nt), the t-siRNA reads were sorted according to their nucleotide distributions and the frequency of each nucleotide (A, C, G, and U) was

Table 2. Response of transgenic cucumber and melon lines to mechanical inoculation with Papaya ring spot virus-W (PRSV-W) and Watermelon mosaic virus (WMV)

\begin{tabular}{lcc}
\hline & \multicolumn{2}{c}{$\begin{array}{c}\text { Percent resistance } \\
\text { (nonsymptomatic/inoculated) }\end{array}$} \\
\cline { 2 - 3 } Lines & PRSV-W & WMV \\
\hline Cucumber 823 & $100(8 / 8)^{\mathrm{a}}$ & $100(9 / 9)$ \\
Cucumber 887 $_{\text {Cucumber control }}^{\mathrm{b}}$ & $0(0 / 6)$ & $100(8 / 8)^{\mathrm{a}}$ \\
Melon 177 $_{\text {Melon 443 }}$ & $0(0 / 4)$ & $0(0 / 4)$ \\
Melon control $^{\mathrm{c}}$ & $0(0 / 8)$ & $0(0 / 5)$ \\
\hline
\end{tabular}

${ }^{\text {a }}$ Plants showed no symptoms 28 days postinoculation and quantitative reverse-transcription polymerase chain reaction indicated a low level of virus accumulation.

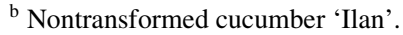

' Nontransformed melon 'Arava'. calculated for each position. The sorted data were divided into two groups: i) cucumber t-siRNAs repeated more than 1,000 times and included 14 different sequences (Fig. 7A, B, E, and F) and ii) melon t-siRNAs repeated more than 100 times and included 16 different sequences (Fig. 7C, D, G, and H). We selected sense and antisense reads of cucumber line 823 and melon line 177 (Fig. 7). In general, very similar patterns of A, $\mathrm{C}, \mathrm{G}$, and $\mathrm{U}$ frequencies were observed in melon and cucumber in the sense orientation (Fig. 7A, B, C, and D) and the antisense orientation (Fig. 8E, F, G, and H).

Three common features can be observed for both transgenic hosts (cucumber and melon). i) At the $5^{\prime}$ terminal, U+A were highly abundant-up to approximately $80 \%$. ii) At position 4 , $\mathrm{G}+\mathrm{C}$ were the predominant nucleotides $(>80 \%)$. iii) At position 7 , the $\mathrm{G}+\mathrm{C}$ frequency was low (0 to $10 \%$ ) (Fig. 7). However, many differences can be seen between the sense (Fig. 7B and D) and antisense (Fig. 7F and H) strands. The GC content of the antisense strand fluctuated greatly, from $0 \%$ at positions $11,14,17$, and 18 to $80 \%$ at positions $8,10,12,16,19$, and 21 ; and, at position 20 , only $\mathrm{G}$ was found in the antisense orientation (Fig. 7E through $\mathrm{H}$ ). In the sense orientation, the frequencies of GC and AU were more similar and, from positions 7 through 21 , they were almost equal.

\section{Distribution of t-siRNA}

throughout the transgene in cucumber and melon.

To understand the role of t-siRNA in transgenic ZYMV resistance in cucumber and melon, perfectly matching t-siRNA sequences were aligned and mapped to the HC-Pro transgene segment (657 nt) (Fig. 8). The frequency of each t-siRNA in

\section{A}
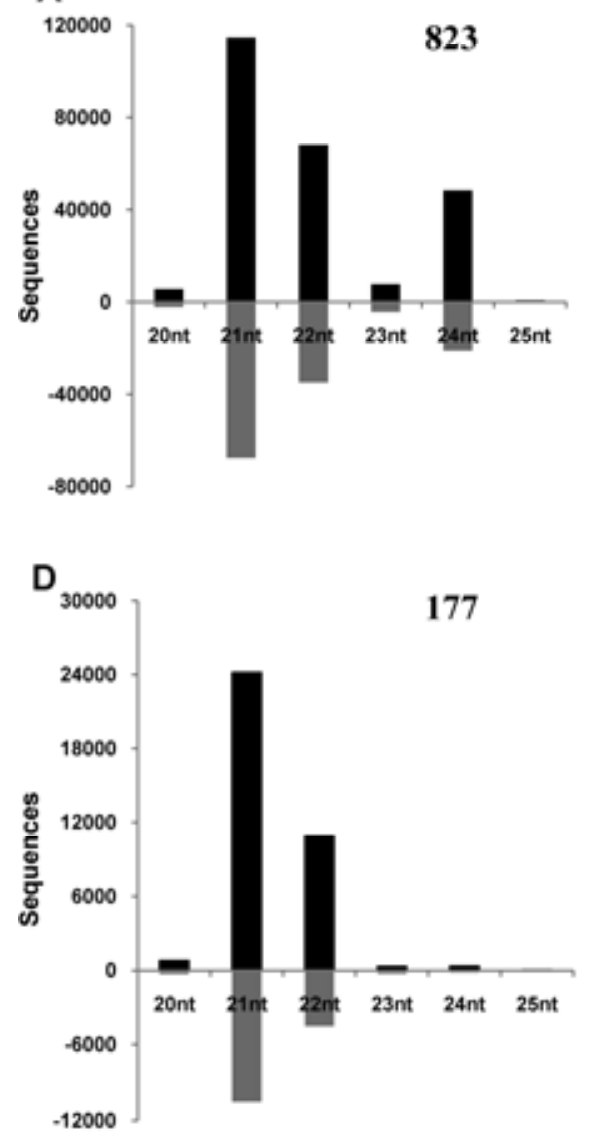

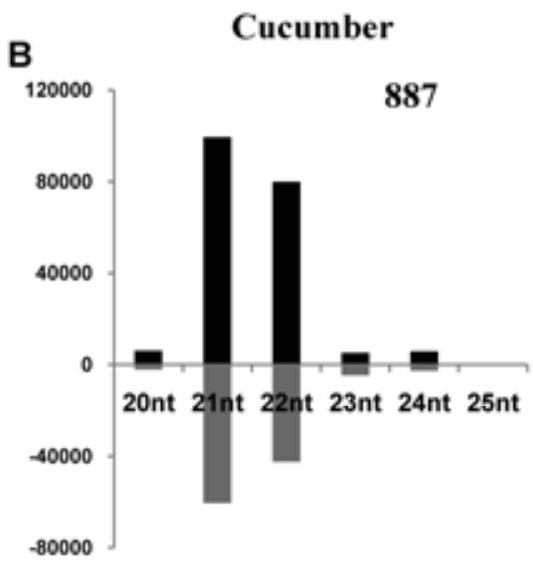

Melon

E

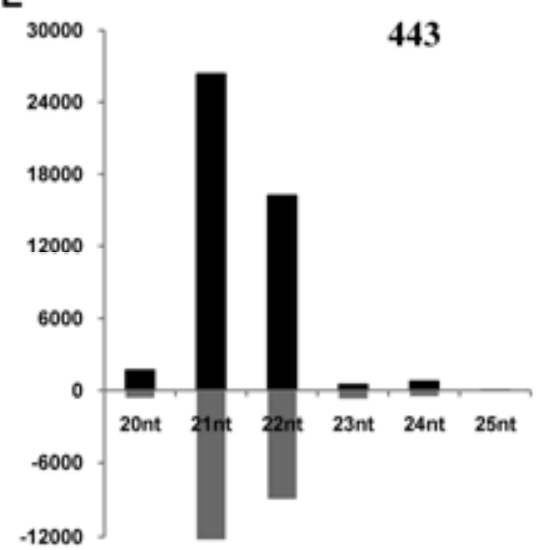

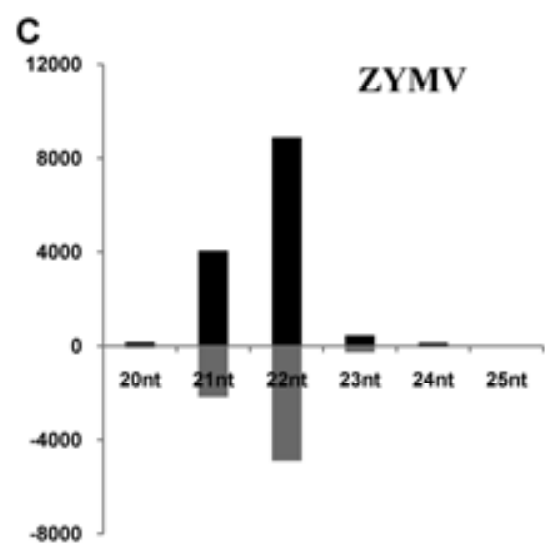

F

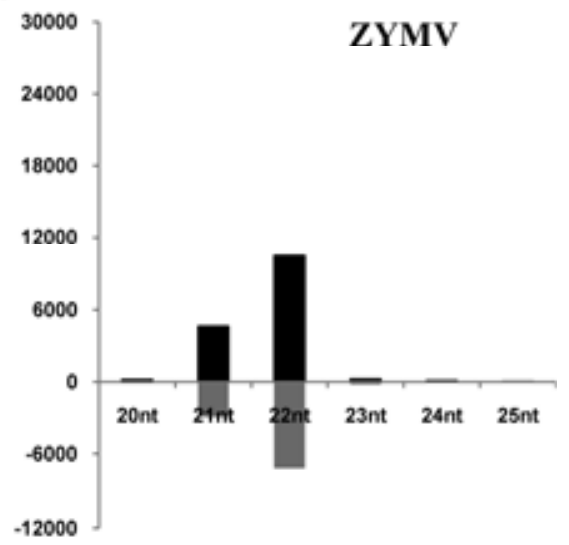

Fig. 6. Size distribution of the transgenic and Zucchini yellow mosaic virus (ZYMV) small-interfering (si)RNA sequences in transgenic cucumber (A, line 823 and $\mathbf{B}$, line 887), transgenic melon (D, line 177 and $\mathbf{E}$, line 443), and nontransgenic ZYMV-infected $\mathbf{C}$, cucumber and $\mathbf{F}$, melon. Histograms show reads per million for each size class between 20 and 25 nucleotides for the sense (above the $x$ axis) and antisense (below the $x$ axis) orientations. 
cucumber lines 823 and 887, melon line 443, and two biological repeats of melon line 177 was calculated and distribution profiles were constructed (Fig. 8). These profiles showed that t-siRNA accumulated in hot-spot regions (peaks) located throughout the transgene (Fig. 8). Seven dominant peaks were mapped, five from the sense sequence (peaks 1, 2, 4, 6, and 7) and two from the antisense sequence (peaks 3 and 5). Each peak included t-siRNA reads of different sizes and covered a region larger than $24 \mathrm{nt}$, due to several overlapping t-siRNA sequences (Supplementary Table 1). For example, the dominant peak 1 in cucumber line 823 (Fig. 8) spans from nucleotide
1,941 to 1,968 and contains t-siRNA reads 21,22 , and $24 \mathrm{nt}$ in length. Within peak 1 , t-siRNA sequences that are $21 \mathrm{nt}$ in size start at a range of positions $(1,941,1,942,1,944,1,945$, and 1,946). Reads of 21,22 , and 24 nt exist in all of the t-siRNA peaks of cucumber line 823, except for peaks 6 and 7, in which no representatives of the 24 -nt class were found. In melon, reads 21 and $22 \mathrm{nt}$ in length were found in all peaks.

Interestingly, very similar profiles were mapped in the transgenic cucumber (lines 823 and 887) and melon (lines 177 and 443). In each line, a similar profile of the same seven peaks was observed, although the numbers of reads in each peak var-
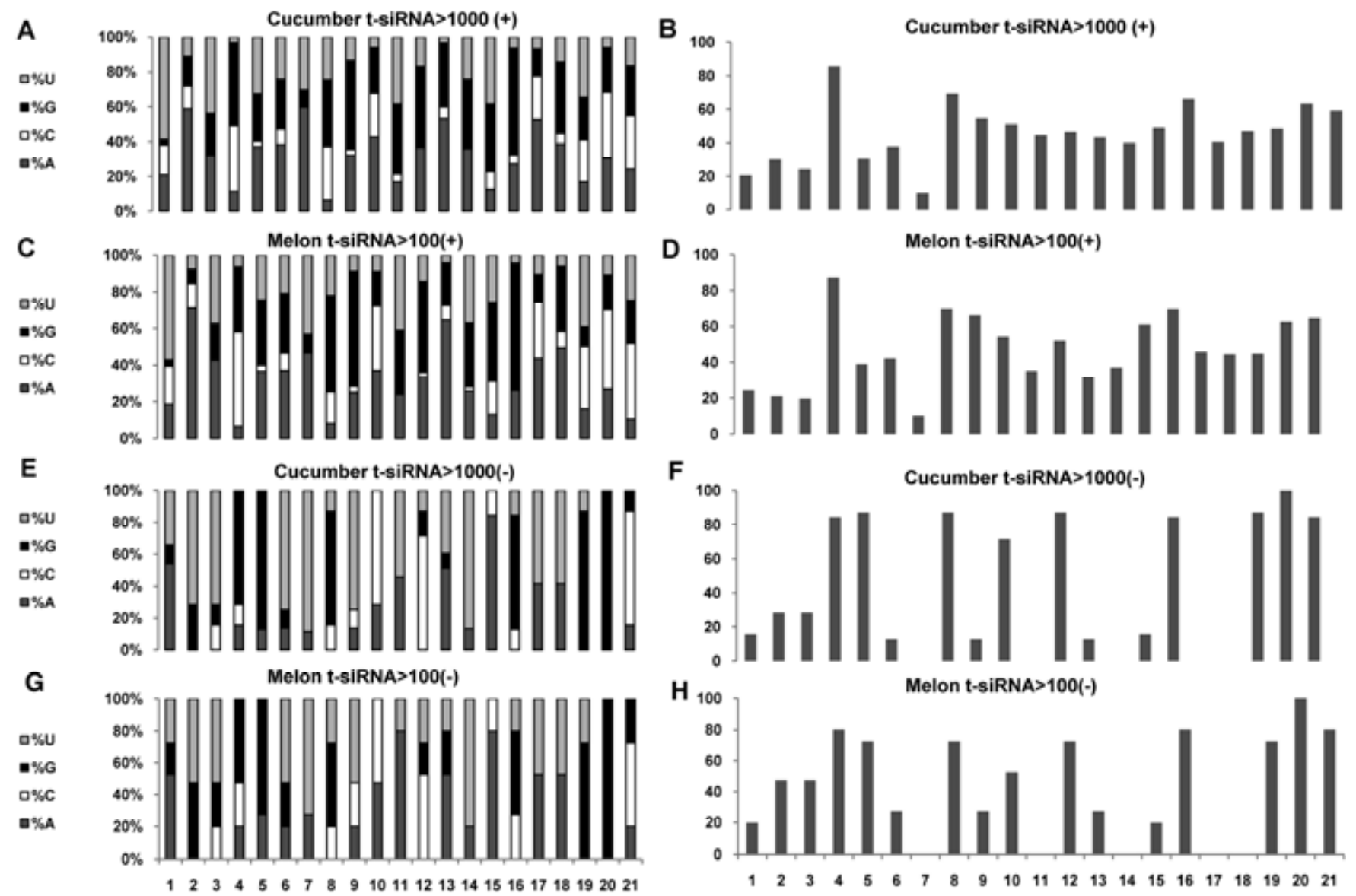

Fig. 7. Distribution of nucleotides (U, G, C, and A) at each position for 21-nucleotide transgenic small-interfering (t-si)RNA sequences from transgenic cucumber (line 823) and transgenic melon (line 177). Each column displays the nucleotide percentage at positions 1 to 21 calculated from the $\mathbf{A}$ and $\mathbf{C}$, sense $(+)$ and $\mathbf{E}$ and $\mathbf{G}$, antisense (-) t-siRNA reads repeated more than 1,000 or 100 times in cucumber and melon. B, D, F, and $\mathbf{H}$, Histograms show the GC content (\%) at each position (1 to 21$)$

Table 3. Percentages of transgenic small-interfering (t-si)RNA and viral small-interfering (vsi)RNA reads of 21, 22 , and 24 nucleotides (nt) in transgenic cucumber and melon and nontransgenic plants infected with Zucchini yellow mosaic virus (ZYMV) ${ }^{\mathrm{a}}$

\begin{tabular}{|c|c|c|c|c|c|}
\hline \multirow[b]{2}{*}{ Lines } & \multirow[b]{2}{*}{ Orientation } & \multicolumn{4}{|c|}{ siRNA length (\% among all small RNA) } \\
\hline & & $21 \mathrm{nt}$ & $22 \mathrm{nt}$ & $24 \mathrm{nt}$ & Other lengths \\
\hline \multirow[t]{2}{*}{ Cucumber823 } & + & 47 & 28 & 20 & 5 \\
\hline & - & 52 & 27 & 16 & 5 \\
\hline \multirow[t]{2}{*}{ Cucumber 887} & + & 54 & 38 & 2 & 6 \\
\hline & - & 51 & 40 & 3 & 6 \\
\hline \multirow{2}{*}{ Melon 177} & + & 66 & 30 & 1 & 3 \\
\hline & - & 66 & 29 & 1 & 4 \\
\hline \multirow[t]{2}{*}{ Melon 443} & + & 60 & 33 & 3 & 4 \\
\hline & - & 58 & 36 & 1 & 5 \\
\hline \multirow{2}{*}{ ZYMV-infected cucumber } & + & 30 & 65 & 1 & 4 \\
\hline & - & 29 & 66 & 1 & 4 \\
\hline \multirow[t]{2}{*}{ ZYMV-infected melon } & + & 29 & 67 & 1 & 3 \\
\hline & - & 28 & 69 & 1 & 2 \\
\hline
\end{tabular}

\footnotetext{
${ }^{a}$ Numbers are percentage of reads per million from total t-siRNA or vsiRNA in sense (+) and antisense (-) orientation. Numbers are rounded up.
} 
ied. Peak 4 was much higher in line 823 than in lines 887, 177, and 443. In peak 4, t-siRNA reads 24 nt in length made up the dominant class. Some differences could be observed between the peaks of the two cucumber lines. For example, a peak was observed upstream of peak 3 in cucumber line 887 that was not present in cucumber line 823 (Fig. 8). In addition, in the biological repeats of the deep sequencing of different samples of melon line 177 (177[1] and 177[2]) (Fig. 8), the peaks upstream of peak 3 and downstream of peak 6 were not observed in both samples; whereas peaks 1 to 7 were seen in both samples. Interestingly, although t-siRNA is generated from perfectly matched transgenic dsRNA, peaks were not observed at the same positions in the sense and antisense orientations (Fig. 8).

The fact that similar t-siRNA distribution patterns were observed in five independent biological tests of different transgenic lines (Fig. 8) indicates a sequence bias in the t-siRNA population. To test whether this bias depends on a nucleotide sequence preference, a vsiRNA sequencing analysis was per- formed using material from nontransgenic cucumber and melon plants that had been infected with ZYMV and were sampled 7 dpi. Surprisingly, profiles of virus-derived vsiRNA were very similar to the seven t-siRNA peaks obtained for the transgene in the relevant region (Fig. 8, lower panel). vsiRNA peak magnitude was approximately $10 \%$ of that observed for the t-siRNA. In addition, vsiRNA fragments from the 21- and 22nt size classes were found in all melon peaks. In contrast, in peaks 5 and 7 of cucumber, only 22-nt reads were found.

\section{Are t-siRNA fragments from the peaks essential} for the maintenance of virus resistance?

We assume that the great abundance of t-siRNA fragments in the observed peaks is probably due to the t-siRNA sequence preferences of the AGO proteins that slice the target virus RNA. We hypothesized that ZYMV resistance in transgenic lines might be the result of the cleavage of the ZYMV genome at sequences complementary to t-siRNA fragments from those

\section{Cucumber}

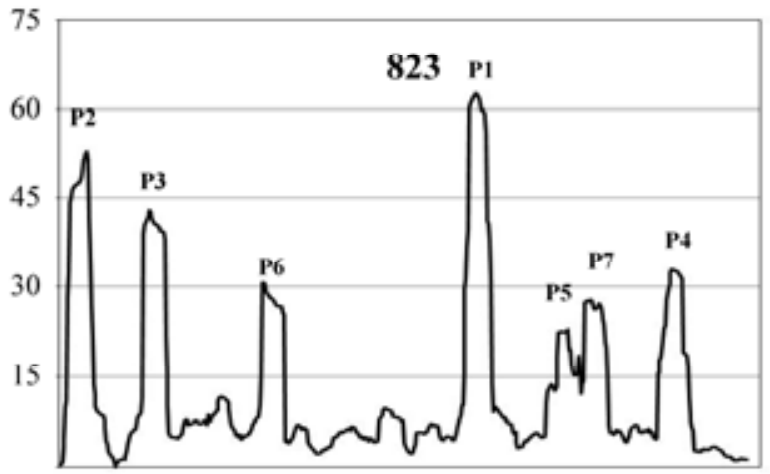

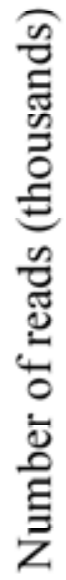
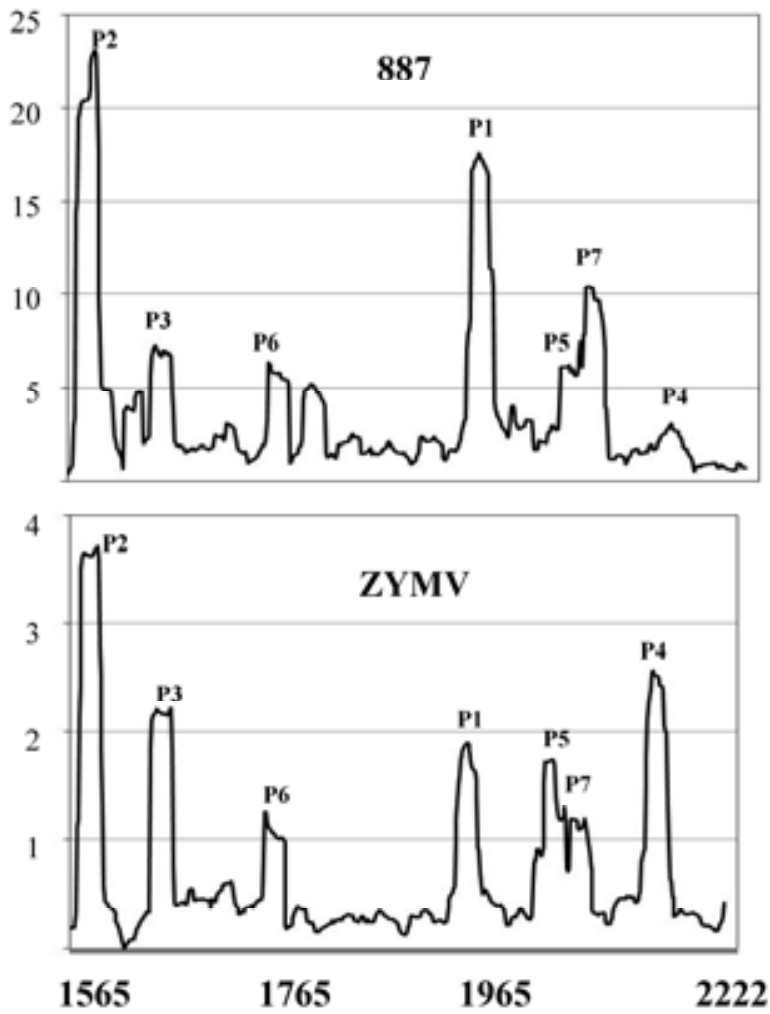
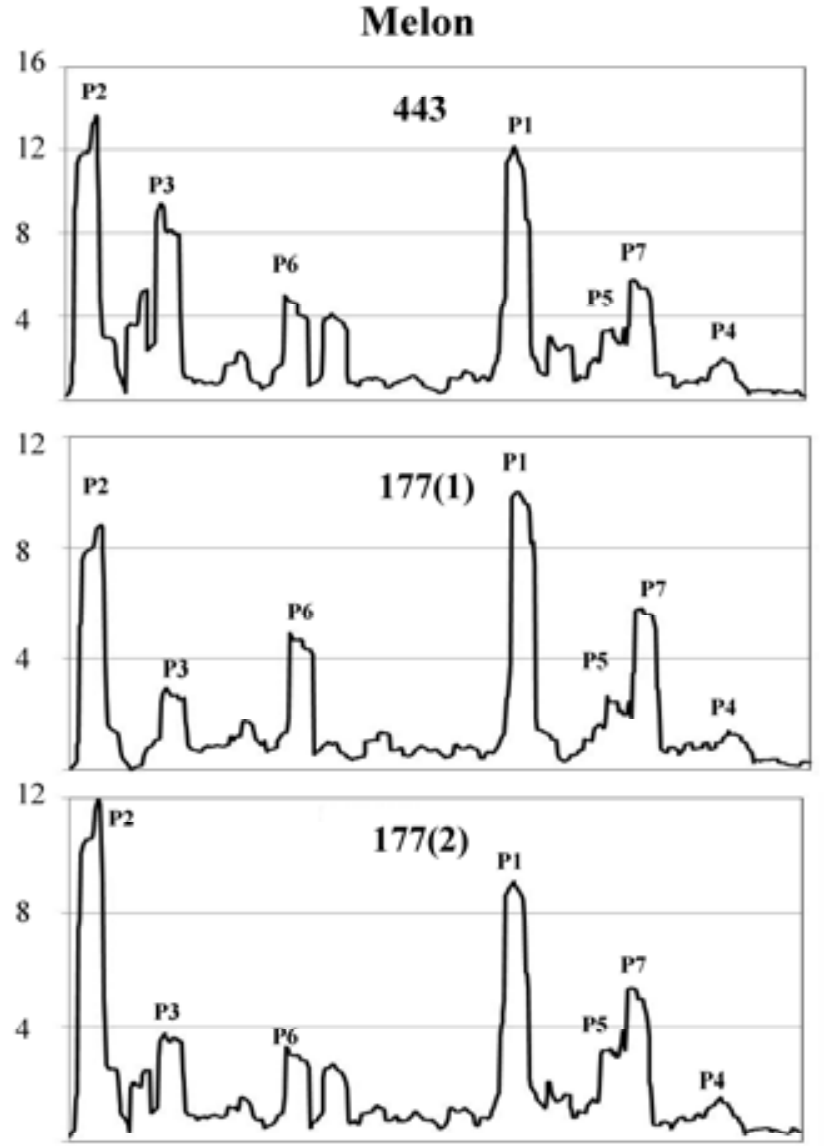

4

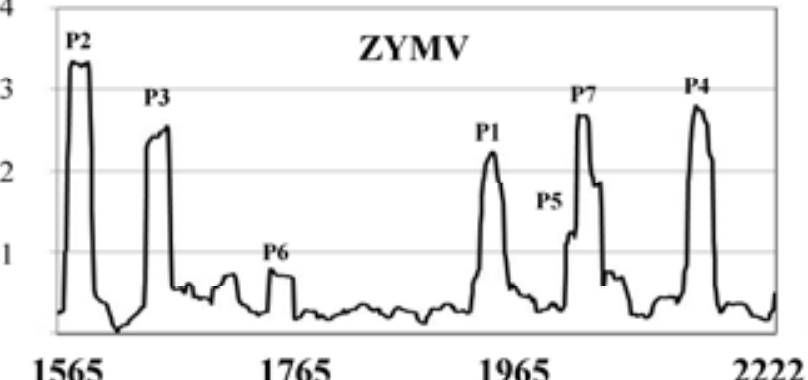

Fig. 8. Transgenic small-interfering (t-si)RNA and viral small-interfering (vsi)RNA accumulation mapped to the transgene in transgenic cucumber (lines 823 and 887), transgenic melon (lines 177[1 and 2] and 443), and nontransgenic Zucchini yellow mosaic virus (ZYMV)-infected cucumber and melon plants. Number of reads $(y$ axis $\times 1,000)$ of perfectly matched siRNA (per million fragments of small RNA) were plotted to the positive (peaks $1,2,4,6$, and 7 ) and negative (peaks 3 and 5) strands of the transgene ( $x$ axis). Note that the scale used for the transgenic plants is different from that used for the nontransgenic, ZYMV-infected plants. 
peaks. If so, disrupting these homologies would decrease virus resistance. To explore this assumption, we generated ZYMV mutants in which the sequences of each peak were altered while the amino acid sequences were unchanged (seven silent mutations within a 21-nt region). Six ZYMV mutants were constructed (Fig. 9), five with sequence changes at sites homologous to peaks P2, P3, P4, P5, and P7 and one control mutant with mutations in a non-peak (nP) region (Fig. 9). Three additional ZYMV mutants were also constructed. One of these mutants contained nucleotide changes in all seven peaks (ZYMV-P[1-7]) and the two other ZYMV mutants had silent mutations every 10 or 6 nucleotides within the transgene region, (ZYMV-Mu10 and ZYMV-Mu6, respectively) (Fig. 9). ZYMV-Mu10 and ZYMV-Mu6 contained 67 and $110 \mathrm{nt}$ changes, respectively, which created virus mutants with 90 and $83 \%$ homology within the transgene sequence.
All nine ZYMV peak mutants systemically infected squash plants and sequencing of the progeny viruses indicated stability of the altered sequences in ZYMV genome. ZYMV mutants P2, P3, P4, P5, P7, and $\mathrm{nP}$ accumulated to levels similar to that of the wild-type ZYMV (Fig. 9B) and induced severe disease symptoms. However, mutants ZYMV-Mu10 and ZYMV-Mu6 accumulated to lower levels than the wild-type ZYMV (Fig. 9B) and induced only mild symptoms in squash. Surprisingly, all nine ZYMV peak mutants were unable to break the resistance of cucumber line 823 following mechanical inoculation, as verified by RT-PCR and back inoculation of squash plants (data not shown). Similarly, the ZYMV mutants ZYMV-P(1-7) and ZYMV-Mu10 were unable to break the resistance of cucumber line 887 and melon lines 423 and 177. This may indicate that t-siRNA sequences other than those accumulated in peaks are involved in ZYMV cleavage. Therefore, despite two
A

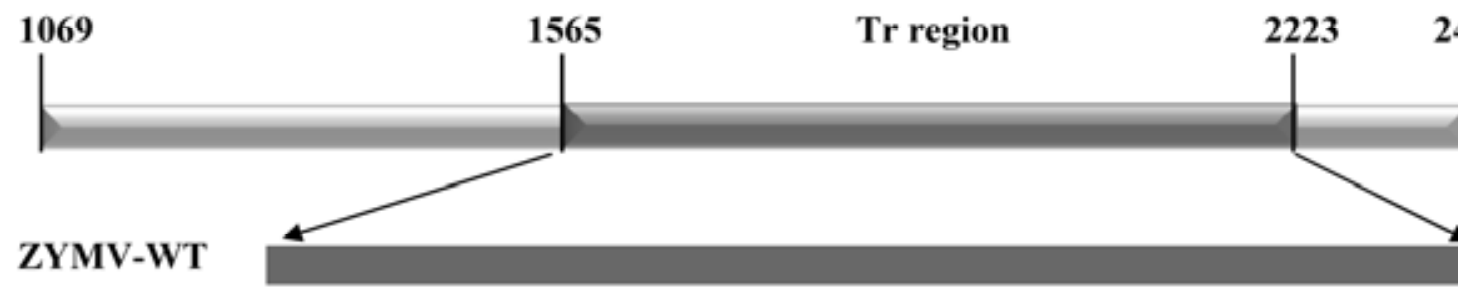

ZYMV-P2

ZYMV-P3

ZYMV-P4

ZYMV-P5

ZYMV-P7

ZYMV-nP

ZYMV-P(1-7)

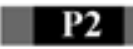

P3

$\begin{array}{lllll}\text { P1 } & \text { P } 5 & \text { P7 }\end{array}$

ZYMV-Mu(10)

ZYMV-Mu(6)

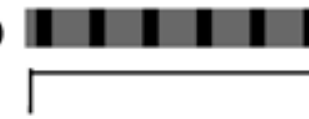

1565

HC-Pro
Symptoms on squash

$\mathbf{S}$

S

S

S

S

S

S

S

M

M

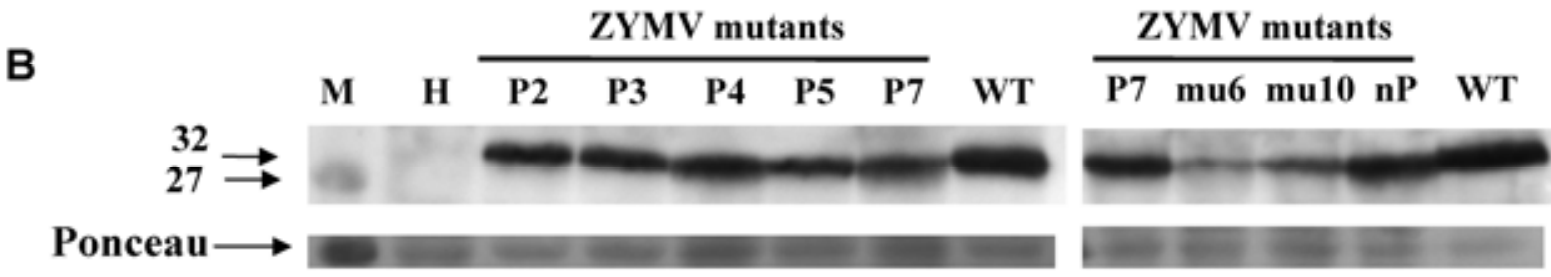

Fig. 9. Zucchini yellow mosaic virus (ZYMV) mutants did not break the resistance of cucumber line 823. A, Schematic representation of the mutated transgenic (tr) region of the HC-Pro (upper panel) of ZYMV infectious clones. Each clone contained mutations corresponding to transgenic small-interfering (tsi)RNA peaks (black rectangles). ZYMV mutants were named according to the peak numbers (P2, P3, P4, P5, and P7), including mutants harboring mutations in all of the peaks (P[1-7]) and one control mutant with a mutation in a non-peak region (nP). ZYMV mutants Mu(10) and Mu(6) contain nucleotide changes every 10 or 6 nucleotides, respectively, in the transgene region. The severity of disease symptoms on squash-severe (S) or mild (M) - is indicated. B, Western blot analysis of ZYMV coat protein accumulation (32 kDa) in squash plants infected with mutated ZYMV or wild-type (WT) ZYMV. Molecular protein markers $(\mathrm{kDa})$ are shown on the left. Membranes were stained with Ponceau staining solution as a protein-loading reference. 
or three mismatches between the t-siRNA sequences and ZYMV RNA (as in the cases of ZYMV-Mu10 and ZYMVMu6), we can conclude that such t-siRNA fragments are sufficient for the slicing of the virus genome and the maintenance of ZYMV resistance.

\section{Expression level of genes essential for PTGS in the transgenic lines.}

Cucumber line 823 exhibited features notably different from those observed for the other transgenic cucurbits, including i) much greater accumulation of t-siRNA ( $43.5 \%$ of small-RNA), ii) accumulation of significantly more representatives of the 24-nt class of t-siRNA, and iii) broader resistance to Potyvirus spp. and ZYMV mutants. It is also possible that, in this line, PTGS is more efficient or essential components in the PTGS system were induced to higher levels.

We examined the expression levels of AGO1, RDR1, RDR6, and DCL4 in line 823 compared with the other transgenic cucurbit lines. AGO1 antiserum showed specificity to cucurbit AGO1 but did not detect AGO1 from Nicotiana benthamiana (Fig. 10A and data not shown), because there was little sequence identity to the $N$. benthamiana protein. Interestingly, in transgenic cucumber lines 823 and 887, AGO1 protein accumulated to a higher level than in control cucumber plants (Fig. 10B) and a slightly higher level of AGO1 protein was detected in line 823 than in 887 . Three biological repeats of these experiments were conducted and the difference between the two lines was consistent (data not shown). However, in transgenic and nontransgenic melon lines, similar levels of AGO1 were detected (Fig. 10C). To analyze whether the accumulation of AGO1 protein is derived from increased mRNA levels, we conducted a Q-RTPCR analysis. We found that AGO1 mRNA levels significantly increased (approximately twofold) in the cucumber plants of line 823 at 14, 28, and 42 days after germination (Fig. 11).

This increased level of AGO1 could be the result of increased transcription due to virus infection (Varallyay et al. 2010) or a decreased level of miR168, which regulates AGO1 mRNA (Vaucheret et al. 2004). Therefore, we examined the accumula-
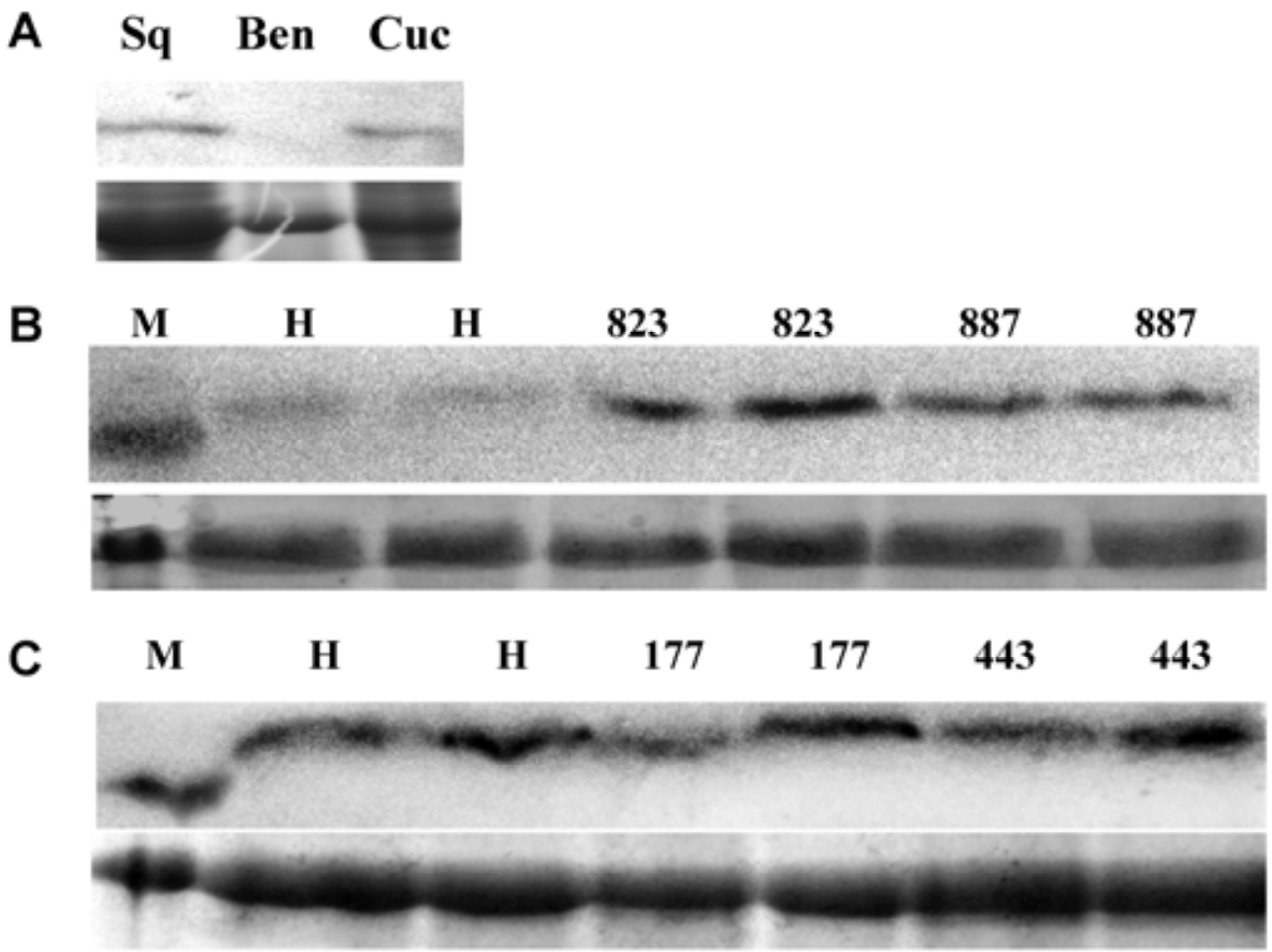

D

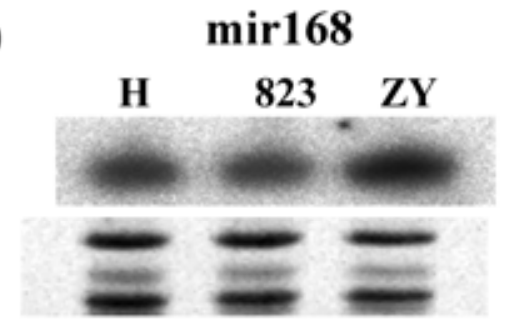

mir159

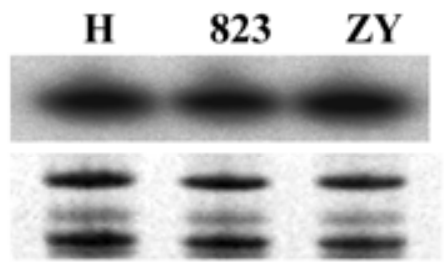

$\operatorname{mir390}$

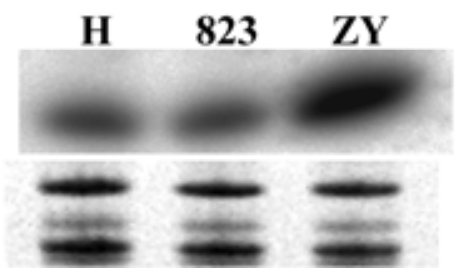

Fig. 10. Analysis of Argonaute 1 (AGO1) protein expression and miR168 accumulation in transgenic cucumber and melon. Western blot analysis of AGO1 protein from total plant extracts of A, nontransformed squash (Sq), Nicotiana benthamiana (Ben), and cucumber (Cuc); B, transgenic cucumber lines 823 and 887; and $\mathbf{C}$, and transgenic melon lines 177 and 443. Transgenic and nontransgenic uninoculated control cucumber and melon (H) samples were collected 14 days postgermination. Leaf extract $(30 \mu \mathrm{l})$ from the second leaf of each of three plants in each sample was loaded and separated in a $8 \%$ sodium dodecyl sulfate acrylamide gel and transferred to a Protran membrane. AGO1 polyclonal antibodies (1:200) were used for membrane hybridization (A, B, and C). D, Accumulation of miR168, miR159, and miR390 in nontransgenic, uninoculated control plants $(\mathrm{H})$, transgenic cucumber line 823, and cucumber infected with Zucchini yellow mosaic virus (ZYMV) (ZY). Aliquots of total RNA (10 $\mu \mathrm{g})$ isolated from three plants per treatment were loaded into each lane. The Northern blot was treated with ${ }^{32} \mathrm{P}$-end-labeled antisense probes corresponding to the miRNA sequences. Ethidium bromide (EtBr) staining in the tRNA zone is shown as an equal-loading control. AGOI mRNAs from squash, cucumber, and melon were cloned based on sequence homology in GenBank (data not shown). Polyclonal antibodies to cucurbit AGO1s (B and C) were raised against a 15-amino-acid sequence from the variable region of the $\mathrm{N}^{\prime}$ terminus region. Expression of AGO1 protein was detected only in the cucurbit hosts and not in N. benthamiana (A). 
tion of miR168 in transgenic cucumber line 823 and nontransgenic plants infected (or not infected) with ZYMV; miR 159 and miR 390 were used as controls (Fig. 10D). The levels of miR168 and the control miRNAs were similar in transgenic line 823 and nontransgenic cucumber 'Ilan' (Fig. 10D). However, increased levels of miR168 and miR390 were observed in ZYMV-infected control cucumber (Fig. 10D), as previously demonstrated by Shiboleth and associates (2007). These data indicate that the higher level of AGO1 in line 823 compared with nontransgenic cucumbers is due to increased transcription, as detected by Q-RT-PCR (Fig. 11). In contrast to cucumber, similar levels of AGO1 protein were observed in transgenic and nontransgenic melon plants (Fig. 10B). This observation supports the discovery of similar levels of AGO1 mRNA (detected by Q-RT-PCR) (Fig. 11).

Interestingly, a significant increase in RDR1 (fivefold) was measured at 14, 28, and 42 days after germination only in transgenic cucumber line 823 and not in line 887 or the control nontransgenic cucumber (Fig. 11). No significant differences in RDR1 levels were observed between cucumber line 887 and the nontransformed cucumber, or between transgenic melon and the nontransformed melon plants (Fig. 11). However, levels of RDR6 were higher (1.5- to 2.5-fold) in transgenic lines (cucumber and melon) than in nontransgenic plants of different ages, except for cucumber line 887 at 42 days after germination. The level of DCL4 mRNA in cucumber line 823 increased approximately twofold for the period of 14,28 , and 42 days after germination. There was no difference in the level observed in transgenic compared with nontransgenic melon, except for the increased level observed in transgenic melon lines at 42 days after germination (Fig. 11). No significant amounts of DCL2 could be detected (data not shown).

\section{DISCUSSION}

ZYMV resistance in transgenic cucumber and melon lines is correlated with $t$-siRNA accumulation.

RNA-mediated resistance in transgenic plants has been shown to confer a high level of resistance against many RNA viruses (Eamens et al. 2008; Prins et al. 2008). In most cases, this resistance is based on PTGS, in which the silencing product (the t-siRNA molecule) is guided by AGO1 to slice viral RNA based on sequence complementation (Ding and Voinnet 2007). This resistance is necessarily sequence specific and limited to virus strains sharing a high level of sequence homology (Ding 2010; Gaba et al. 2010; Prins et al. 2008). In this study,
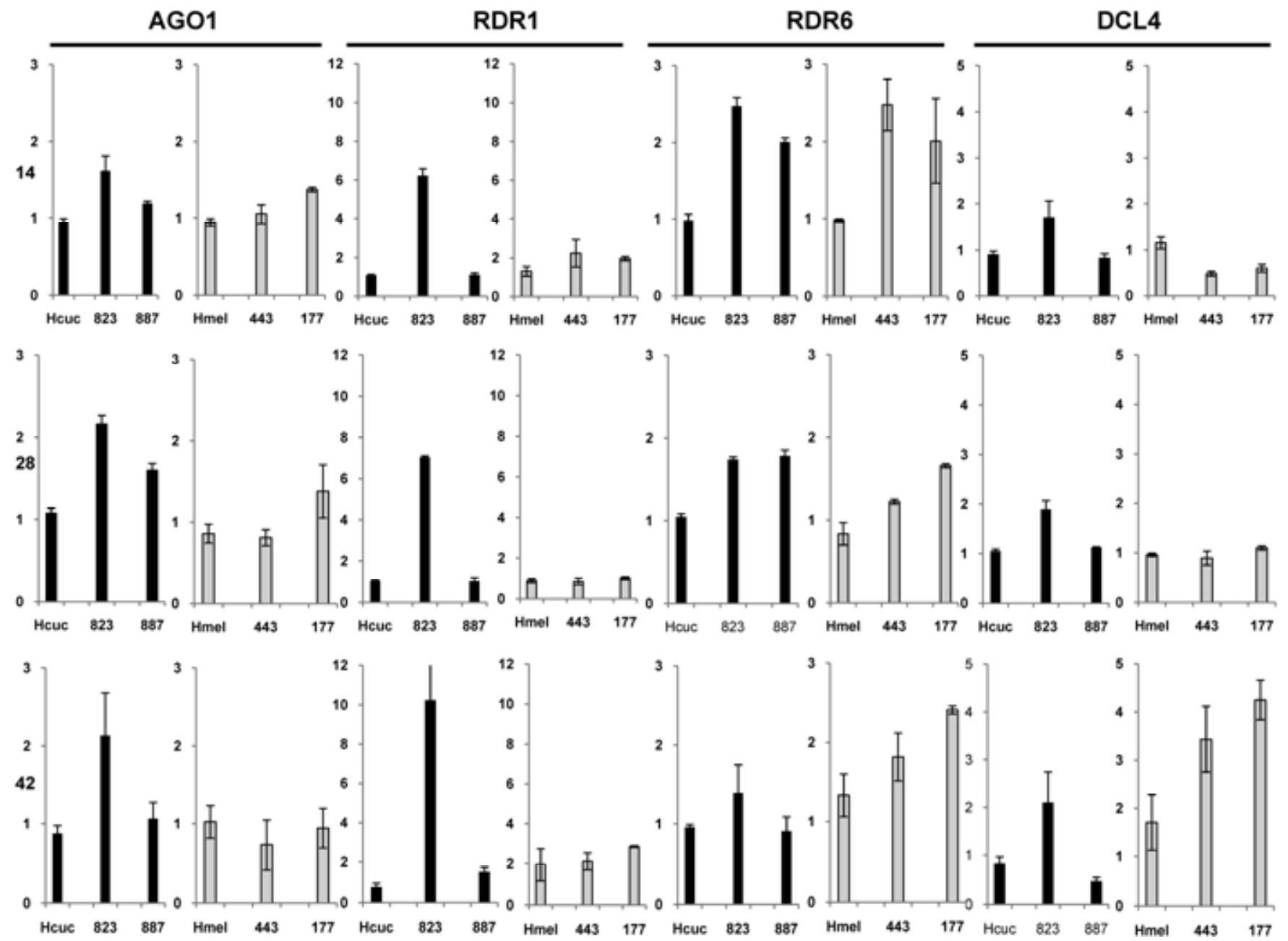

Fig. 11. Expression of Argonaute 1 (AGO1), RNA-dependent RNA (RDR)1, RDR6, and DCL4 mRNA in transgenic and nontransgenic cucumber (in black) and melon (in gray). Total RNA was extracted from transgenic cucumber (lines 823 and 887) and melon (lines 177 and 443 ) and from nontransgenic cucumber and melon $(\mathrm{H})$. This total RNA was extracted from three plants of each line 14, 28, and 42 days after germination (dpg). First-strand cDNA was constructed using Oligo-dT. Quantitative reverse-transcription polymerase chain reaction was performed with appropriate primers for AGO1, RDR1, RDR6, DCL4, and the F-box or normalization (accession GW881870). The relative expression level of each gene was calculated using the $\Delta \Delta$ cycle threshold method normalized to the F-box gene. Each histogram represents the mean of three replicates of each of two biological repeats. Bars represent the standard deviations of the means. 
we show, for the first time, broader resistance to several Potyvirus spp. in transgenic cucumber expressing a high level of ZYMV t-siRNA. We attempted to explain this unique resistance by characterizing t-siRNA sequences using Illumina highthroughput sequencing and the expression profiles of endogenous genes associated with PTGS. We investigated four transgenic lines of melon and cucumber for three categories of plant characteristics: virus resistance; t-siRNA accumulation; and the expression profiles of AGO1, RDR, and DCL. The transgenic cucumber lines were "immune" (completely resistant) to systemic ZYMV infection and the transgenic melon lines exhibited high levels of resistance.

A few instances of resistance breaking were observed in the transgenic melon lines. This resistance-breaking cannot be explained by mutations in the progeny virions because the ZYMV sequence was unchanged. It can, however, be explained by the relatively low level of t-siRNA in melon ( 6 and $8 \%$ of total small-RNA) compared with cucumber (13 and 43\%), as determined by deep sequencing (Fig. 2). Similar correlations between t-siRNA levels and resistance have been described for ZYMV in melon and watermelon (Citrullus lanatus Thunb.) (Wu et al. 2009; Yu et al. 2010), as well as for other plant viruses (Patil et al. 2011; Qu et al. 2007), although t-siRNA accumulation is not always sufficient to induce resistance to RNA viruses (Lopez et al. 2010). It is also possible that the tsiRNA level varied between segregating transgenic melon plants ( $\mathrm{T}_{3}$ generation) due to co-suppression of transgene copies (five copies in line 177 and two copies in line 432) (Fig. 1C). A significantly lower level of t-siRNA may have accumulated in the plants in which resistance was broken, as reported recently for melon resistance to ZYMV (Wu et al. 2009).

\section{High level of transgenic viral small-RNA associated with broad Potyvirus sp. resistance in cucumber lines.}

Unexpectedly, the transgenic cucumber lines 823 and 887 exhibited resistance to cucurbit Potyvirus spp. WMV and PRSV-W, in addition to ZYMV, despite relatively low homology to the ZYMV HC-Pro transgene (Figs. 4 and 5). Broader resistance to cucurbit Potyvirus spp. has been achieved through the expression of coat protein (CP) in transgenic squash (Fuchs and Gonsalves 1995). In addition, RNA-mediated viral resistance in transgenic plants based on PTGS has been observed in cases in which the transgene was quite homologous with the target virus or specific strains thereof (Bouche et al. 2006; Bucher et al. 2006; Gaba et al. 2010; Lindbo and Dougherty 2005; Prins et al. 2008). The relationship between t-siRNA and virus resistance was demonstrated elegantly by the expression of an artificial miRNA containing a 21-nt viral sequence in transgenic plants (Niu et al. 2006).

In our study, alignment of the ZYMV-HC-Pro transgene sequence with the corresponding regions of WMV and PRSV-W indicated 67 and $63 \%$ homology between the transgene and these two viruses, respectively. Sequence homology to ZYMV is spread throughout the transgene sequence: zones of 11- and 12-nt homology are the largest regions found for WMV and PRSV-W, respectively (Fig. 5). Therefore, if cleavage of the WMV and PRSV-W RNA genomes is a result of RISC guided by t-siRNA, there must be at least two sequence mismatches. Mismatches between siRNA and target genes are common in miRNA (Brodersen and Voinnet 2009) and can reach five mismatches for miR319 and its TCP target gene (Palatnik et al. 2007).

Using a program designed to predict the miRNAs' target genes, we investigated whether t-siRNA sequences from transgenic cucumber line 823 corresponded to putative targets in the corresponding HC-Pro regions of WMV and PRSV-W. We found one putative t-siRNA target sequence for cleavage in each virus and three putative t-siRNAs for translation inhibition. These t-siRNAs are not from the highly abundant t-siRNA sequences (peaks) and additional study is required to clarify their importance for Potyvirus sp. resistance in line 823.

It is not clear why cucumber line 823 exhibited immunity to systemic WMV infection and resistance (low-level symptomless viral RNA accumulation) to PRSV-W. It is possible that the homology differences with the ZYMV transgene sequence (67 and 63\% for WMV and PRSV-W, respectively) can explain the variation in the resistance to these two viruses, as has been demonstrated for resistance to potato and tomato strains of PVY in transgenic tobacco transformed with an inverted repeat (IR)-replicase-PVY construct (Gaba et al. 2010).

In addition, the Israeli strain of PRSV-W induces very severe symptoms in cucurbits compared with the moderate symptoms induced by WMV-Is. It has been suggested that the severity of symptoms is associated with HC-Pro affinity binding to the siRNA-duplex, as demonstrated previously for ZYMV (Shiboleth et al. 2007). Based on this assumption, it is possible that the PRSV-W HC-Pro possesses a stronger suppressor with a higher binding affinity for transgene siRNA-duplex than WMV, which permits the systemic movement of PRSV-W in transgenic cucumber line 823. In transgenic cucumber line 887, a similar resistance trend was observed: namely, partial resistance to WMV (symptomless with very low viral RNA accumulation) and susceptibility to PRSV-W.

The question remains as to why resistance to WMV and PRSV-W is stronger in line 823 than in line 887 . Very similar distributions of t-siRNA peaks throughout the transgene sequence were observed in the two lines (Fig. 8). However, differences were observed in the number of reads and the size distribution of the t-siRNA fragments in lines 823 and 887. In line $823,20 \%$ of the t-siRNA fragments are 24 nt long (Table 3), a size which is hardly found in line 887 . However, 24-nt-long t-siRNA fragments are probably not involved in antiviral silencing, as shown for TuMV infection of Arabidopsis (Garcia-Ruiz et al. 2010), in which only 21- and 22-nt-long fragments of tsiRNA are important. The relevant number of t-siRNA fragments in line 823 account for approximately $34 \%$ of the total tsiRNA (excluding 24-nt fragments). This figure is 2.5 times greater than that for line $887(12.7 \%)$. Because only a small fraction of t-siRNA is probably loaded into the RISC complex, it is possible that most of the t-siRNA (including $24 \mathrm{nt}$ ) served as primers for secondary amplification of dsRNA subsequently cleavage by DCL. Therefore, we assume that the broader viral resistance of cucumber line 823 compared with line 887 is due to the relative quantities of 21- to 22-nt-long t-siRNA fragments, which may be more easily loaded into the RISC complex or escape sequestration by HC-Pro by sheer numbers.

\section{High level of t-siRNA accumulation correlates with increased expression of endogenous genes involved with PTGS.}

We observed significant increases in the amount of RDR1 mRNA (6- to 10-fold) in line 823 in plants of different ages (Fig. 11). RDR1 has been reported to be responsible for the production of the vast majority of vsiRNA of TuMV, Tobacco mosaic virus, and Tobacco rattle virus (Donaire et al. 2008; Garcia-Ruiz et al. 2010; Qi et al. 2009). A reduced level of RDR1 is associated with susceptibility to virus infection (Rakhshandehroo et al. 2009) and an increased level of viral RNA has been associated with the infection of $r d r l$ plants with a CMV 2b mutant (Wang et al. 2010). Therefore, we suggest that the increase in the RDR1 level observed in line 823 may be induced by a high level of transgenic dsRNA expression, similar to that associated with virus infection (Xie et al. 2001; Yu et al. 2003), as t-siRNA accumulates and eventually ac- 
counts for $43 \%$ of total plant small RNA. This may imply that RDR 1 is the primary responder to the presence of viral RNA ( $\mathrm{Qu}$ 2010) and that its expression is induced by a threshold level of dsRNA expression in cucumber line 823 (but not in 887 or the transgenic melon lines).

In addition to RDR1, smaller increases in the levels of RDR6, DCL4, and AGO1 mRNA and protein were observed in line 823 than in line 887 and the control plants (Fig. 11). Based on this observation, we think that the broad resistance of line 823 may be due to the combination of high levels of expression of transgenic dsRNA and the activation of a set of endogenous genes involved in defending the plant against viral infection, particularly RDR1. It is possible that the resistance to WMV and PRSV-W observed in line 823 is due to a high level of t-siRNA, which serves as a primer for RDR1 to synthesize aberrant WMV or PRSV-W viral dsRNA, leading to viral resistance. However, the increased levels of RDR1 and AGO1 observed in line 823 were insufficient to reduce the level of CMV RNA, probably due to the absence of priming (ZYMV t-siRNAs have no sequence homology with CMV) and the inhibition of RDR 1 activity by the CMV $2 b$ suppressor (Wang et al. 2010).) Based on the above hypothesis, we assume that, in melon lines 443 and 177, the relatively low level of t-siRNA and increased level of RDR6 (but not RDR1, AGO1, or DCL4) are not sufficient to confer resistance to the heterologous viruses WMV and PRSV-W, although they do confer resistance against the homologous virus ZYMV.

\section{The t-siRNA profile exhibits a sequence bias similar to that observed for ZYMV siRNA.}

Sequence analysis of five t-siRNA libraries from transgenic cucumber and melon lines revealed very similar t-siRNA features (Figs. 6, 7, and 8). Therefore, we assume that, although libraries were sequenced only once for lines 823,887 , and 423 and biological repeats performed only for line 177 , it is improbable that the observed similarities are random because the multiplicity of libraries can be considered a form of biological repeats.

In parallel to the t-siRNA libraries, we constructed additional siRNA libraries of ZYMV-infected cucumber and melon, which enabled us to compare (for the first time) the t-siRNA and vsiRNA sequences generated from the same sequence. A number of unique features can be observed in these t-siRNA libraries:

i) t-siRNA sequences were only found in the stem region (657 nt of HC-Pro) of the IR construct and not in the intron loop region, as was reported in recent studies concerning IRgreen fluorescent protein (GFP) constructs in transgenic Arabidopsis (Dunoyer et al. 2010a; Molnar et al. 2010). Therefore, the intron is excised prior to secondary amplification by RDR. In addition, t-siRNA fragments were found to cover $98 \%$ of the transgenic region, suggesting that DCL cleavage may occur at any locus in the transgene dsRNA, as has been demonstrated for several viruses (Donaire et al. 2009).

ii) The 21-nt length class was the dominant t-siRNA population, as determined by sequencing (Table 3 ) and Northern blotting (Fig. 1), as has been reported for plants transformed with IR-GFP constructs (Molnar et al. 2010). Approximately 35\% of the total t-siRNA was $22 \mathrm{nt}$ in length (Table 3), based on sequencing data. However, sequences of this size cannot be observed by Northern blotting, probably because of the difficulty of separating 21-nt fragments from 22-nt fragments on an acrylamide gel or preferential probe binding to the dominant population of 21-nt t-siRNA. Similarly, only the dominant size of $22 \mathrm{nt}$ (approximately 67\%) of ZYMV siRNA can be detected by Northern blot analysis, in which the siRNA fragments migrate through the gel slightly more slowly than t-siRNA
(Fig. 1), although approximately $33 \%$ of vsiRNA population are $21 \mathrm{nt}$ long, as determined by sequencing. It is also possible that both methylated and nonmethylated t-siRNA and vsiRNA are present, a combination that would affect our ability to distinguish between 21- and 22-nt small RNA fragments, because methylated siRNA runs more slowly on acrylamide gels (Lozsa et al. 2008).

Approximately $35 \%$ of the t-siRNA fragments from the different libraries were $22 \mathrm{nt}$ long (Table 3). siRNA fragments of this size are processed by DCL2 (Deleris et al. 2006) and may induce secondary dsRNA amplification by RDR6, as recently shown for 22-nt miRNA (Cuperus et al. 2010). Recently, an abundance of 22-nt sequences was reported for endogenous IR genes (Dunoyer et al. 2010a) and a low concentration of 22-nt sequences was observed from an IR-GFP construct in Arabidopsis (Molnar et al. 2010). However, in ZYMV-infected plants, a higher proportion of 22-nt compared with 21-nt sequences was observed at an early stage of infection (5 dpi) (Table 3; Fig. 6). This contrasts with findings concerning TuMV siRNA in Arabidopsis at 10 dpi (Garcia-Ruiz et al. 2010). The preponderance of 21- and 22-nt sequences among the t-siRNA and vsiRNA fragments implies a cooperative interaction between DCL4 and DCL2, as has been observed for several viral systemic infections (Dunoyer et al. 2010b; GarciaRuiz et al. 2010; Qi et al. 2009).

iii) t-siRNA produced from the IR construct (637 nt of HCPro) accumulated asymmetrically in hot spots located throughout the transgene sequence, with a higher number of sense counts than antisense. Similarly, asymmetrical siRNA distributions have been recently reported for endogenous IR genes (Dunoyer et al. 2010a) and transgenic plants bearing a nonviral sequence (Molnar et al. 2010). The analysis of seven smallRNA libraries, five from transgenic cucumber and melon and two from ZYMV-infected plants, indicated that t-siRNA is numerically biased to the sense orientation (like ZYMV vsiRNA) and that these sequences are asymmetrically distributed, as previously reported for several RNA viruses (Dunoyer et al. 2010a; Ho et al. 2007; Llave 2010; Molnar et al. 2005; Qi et al. 2009). The similarity of siRNA distribution between tsiRNA with vsiRNA indicate that most of the vsiRNA generated are from viral dsRNA rather than secondary structure. We assume that this distribution of t-siRNA reflects a bias for sequence stability, as has been suggested for vsiRNA (Llave 2010), and is not yet understood. We show here, for the first time, that the distribution of t-siRNA in peaks from an invertedrepeat of a viral sequence shows almost the same pattern as the distribution of vsiRNA from the same region. These data imply that the suppression of gene silencing by ZYMV HC-Pro does not affect the vsiRNA distribution pattern, at least in this region. Therefore, we assume that viral dsRNA, whether from a transgene or the replicative form of a virus, is processed to t-siRNA similarly by DCL4 and DCL2 and also accumulated similarly. Therefore, we can refer to transgenic IR-dsRNA as a viral dsRNA fragment.

The similarity between t-siRNA and vsiRNA indicates that vsiRNA probably originated from fully matching dsRNA and not from an ssRNA secondary structure, as has been suggested for several RNA viruses (Llave 2010). In addition, RDR1 and RDR6 have been shown to be involved with the asymmetric accumulation of sense and antisense vsiRNA (Qi et al. 2009). Thus, it is possible that the asymmetric accumulation of sense and antisense t-siRNA is due to dsRNA processing via amplification of transgene transcripts by RDR1 and RDR6.

iv) There were similarities in the distributions of A, T, G, and $\mathrm{U}$ within a 21 -nt range in the five t-siRNA libraries. At the $5^{\prime}$ end, there was a tendency to start with $\mathrm{U}$ and A (approximately $80 \%$ ) and there was a high frequency of $\mathrm{G}$ and $\mathrm{C}$ at the $3^{\prime}$ end 
(80\%). A similar distribution trend was observed in ZYMV siRNA (data not shown), and this type of trend has also been reported for several other viruses (Donaire et al. 2009; Ho et al. 2010; Qi et al. 2009). Interestingly, different patterns of distribution were observed for the sense and antisense in the t-siRNA libraries (Fig. 8), an issue which requires additional study.

\section{The accumulation of $t$-siRNA \\ in peaks is not essential for virus resistance.}

To study the role of the distribution of t-siRNA in ZYMV resistance, we constructed a series of ZYMV mutants bearing sequences differing from those found at t-siRNA peaks. The fact that none of these mutant viruses, including a mutant with changes in all seven peaks, could break the virus resistance in the transgenic lines (Fig. 9) indicates that t-siRNA accumulation in peaks is not essential for ZYMV resistance. Other t-siRNA fragments, which accumulated to lower levels, are probably associated with RISC viral cleavage leading to resistance. Indeed, it has been shown that t-siRNA of a unique viral sequence constructed from a miRNA precursor is sufficient to induce resistance to RNA viruses (Duan et al. 2008; Niu et al. 2006). In addition, maintenance of resistance in transgenic line 823 against ZYMV mutants with mismatches every 6 and $10 \mathrm{nt}$ within the transgene region (Fig. 9) indicated that two mismatches between the 21-nt t-siRNA and the viral sequence were enough to confer resistance. This finding supports our results concerning resistance against WMV and PRSV-W, for which we noted less than 21 nt of discontinuous homology in the transgenic cucumber line 823 . It possible that the very large amount of t-siRNA in line 823, in addition to directing an association with the RISC complex, also serves as a primer for the amplification of ZYMV dsRNA and secondary vsiRNA processed from this dsRNA, effectively blocking the systemic infection of ZYMV mutants.

\section{MATERIALS AND METHODS}

\section{Construction of the binary vector pART-IR-HC for gene silencing.}

A 657-nt fragment of the HC-Pro of ZYMV (position 1,567 to 2,224 nt of ZYMV genome, accession number EF062582.1) was isolated from an infectious clone by PCR amplification (Gal-On et al. 1991). Each primer was designed with two additional restriction sites to permit cloning in both orientations: forward primer 5'-A GGTACCATCGATACCACATGCATCTG ACTGGTGAG-3' (with added KpnI and ClaII sites underlined) and reverse primer 5'-ATGCTCGAGTCTAGAGTTGCA ACATCCA TCAATGAAG-3' (the added XhoI and XbaI restriction sites are underlined). The HC-Pro fragment was cloned into the pHannibal vector in an inverted repeat orientation and transferred into the pART27 binary vector as described by Wesley and associates (2001).

\section{Transformation of cucumber and melon.}

Cucumber seed (Cucumis sativus L., Ilan) were obtained from Zeraim Gedera Co., Israel. A. tumefaciens-mediated transformation of cucumber was performed as reported previously (Gal-On et al. 2005). Transformed cucumber seedlings $\left(\mathrm{T}_{0}\right)$ of lines 823 and 887 were cross pollinated with nontransgenic, androgynous, open-pollinated cucumber Bet-Alpha and kanamycin-resistant $T_{1}$ seedlings were screened for ZYMV resistance under greenhouse conditions following sap inoculation. ZYMV-resistant hemizygous $\mathrm{T}_{1}$ plants were self pollinated and the $T_{2}$ seed were screened by PCR for the presence of the insert to select homozygous plants. Homozygous (line 823) and hemizygous (887) $\mathrm{T}_{3}$ transgenic cucumbers were used in further experiments.
Melon seed (Cucumis melo L., 'Vedrantais') were planted in potting soil for 10 to 12 days in a growth room at $25^{\circ} \mathrm{C}$ with a 16-h photoperiod. Young, first true melon leaves $(1$ to $3 \mathrm{~cm}$ in width) were used for the transformation. Leaves were surface sterilized for $15 \mathrm{~min}$ in Sodium hypochlorite (5\% active chlorine) solution and rinsed four to six times with sterile water. The petioles were discarded and each leaf was cut into four to eight pieces. The explants were cultured (upside down) in petri dishes containing solidified Murashige-Skoog (MS) medium with 6-benzylamino purine at $0.5 \mathrm{mg} / \mathrm{liter}$, indole 3-acetic acid (IAA) at $0.1 \mathrm{mg} / \mathrm{liter}$, copper sulfate at $1 \mathrm{mg} / \mathrm{liter}$, and $200 \mu \mathrm{M}$ acetosyringone. The cultures were kept in darkness at $25^{\circ} \mathrm{C}$ for 1 to 2 days.

Agrobacterium cultures were grown overnight at $28^{\circ} \mathrm{C}$ in Luria-Bertani medium containing appropriate selective antibiotics and $100 \mu \mathrm{M}$ acetosyringone. Bacteria were precipitated and resuspended in liquid MS medium to a final population density of 0.5 (optical density at $600 \mathrm{~nm}$ ). The explants were dipped into an Agrobacterium suspension for $5 \mathrm{~min}$. Agroinfected explants were blotted dry on sterilized Whatman-1 filter paper to remove excess Agrobacterium on explants surface and returned to the same culture plates for 4 days of co-cultivation in the dark. The explants were then transferred to selection medium consisting of MS medium with 6-benzylamino purine at $0.5 \mathrm{mg} /$ liter, IAA at $0.1 \mathrm{mg} /$ liter, cefotaxime at $500 \mathrm{mg} / \mathrm{liter}$, and kanamycin at $100 \mathrm{mg} /$ liter. Explants were subcultured every 2 weeks. Small shoots were transferred to elongation medium consisting of MS medium supplemented with 6-benzylamino purine at $0.1 \mathrm{mg} / \mathrm{liter}$, copper sulfate at $1 \mathrm{mg} / \mathrm{liter}$, cefotaxime at $500 \mathrm{mg} / \mathrm{liter}$, and kanamycin at $100 \mathrm{mg} / \mathrm{liter}$.

Shoots ( $2 \mathrm{~cm}$ in height) were transferred to rooting medium composed of MS medium supplemented with IBA (indole-3butyric acid) at $2 \mathrm{mg} / \mathrm{liter}$, copper sulfate at $1 \mathrm{mg} / \mathrm{liter}$, cefotaxime at $500 \mathrm{mg} / \mathrm{liter}$, and kanamycin at $100 \mathrm{mg} / \mathrm{liter}$. Rooted shoots were transferred to Jiffy 7 plugs for hardening for 2 weeks. Transformed $\mathrm{T}_{0}$ melon lines 177 and 443 harboring a transgene insert, IR-HC-Pro (IR-HC) (determined by PCR) were self pollinated. Kanamycin-resistant $T_{1}$ seedlings were screened for ZYMV resistance in a greenhouse. ZYMV-resistant $T_{1}$ plants were self pollinated and $T_{2}$ plants resistant to systemic ZYMV infection were used in further experiments.

\section{Inoculation of plants with viruses.}

Squash (Cucurbita pepo L., 'Ma'yan') was used as a source of virus inocula and the infectivity of ZYMV mutants was also evaluated in squash. Squash plants were grown in a temperature-controlled growth room kept at $25^{\circ} \mathrm{C}$ with $24 \mathrm{~h}$ of illumination before and after inoculation. Four viruses-ZYMV (accession number EF062582) (Gal-On and Raccah 2000), WMV (accession number AF322376), PRSV-W (accession number AY027810), and the Fny strain of CMV (Rizzo and Palukaitis 1990) - were used to evaluate the resistance of the transgenic melon and cucumber plants. Inocula were prepared by grinding young squash leaves in distilled water 10 to 14 dpi. Cucumber, melon, and squash seedlings at the cotyledon stage ( 3 to 4 days postemergence) were mechanically inoculated or bombardment inoculated with virus-bearing sap or cDNA of full-length viral clones, as described by Gal-On and associates (1995).

\section{DNA extraction, Southern blotting, and PCR analysis.}

Total genomic DNA was extracted from young leaves (second or third youngest) using the Dellaporta method (Dellaporta et al. 1983) for transgene confirmation and the cetyltrimethylammonium bromide method (Murray and Thompson 1980) for Southern blot analysis. The DNA solution $(1 \mu \mathrm{l})$ was diluted in $25 \mu \mathrm{l}$ of a PCR reaction mixture containing appropriate primers based on the sequence of the HC-Pro gene (accession number 
EF062582). The primers used to evaluate the transgene IR-HC were 5'-ACATGCATCTGACTGGTGAG-3' (P1-sense) and 5'AGTTGCAACATCCATCAATGAA-3' (P2-antisense). PCR conditions were $2 \mathrm{~min}$ at $94^{\circ} \mathrm{C}$; followed by 30 cycles of $30 \mathrm{~s}$ each at 94,58 , and $72^{\circ} \mathrm{C}$; and a 5 -min elongation step at $72^{\circ} \mathrm{C}$. For the Southern blot analysis, total plant DNA was digested with EcoRV overnight to determine the transgene copy number. Comparable amounts of DNA $(50 \mu \mathrm{g})$ were loaded onto a $1 \%$ agarose gel, separated by electrophoresis overnight at $32 \mathrm{~V}$, and then blotted onto Hybond-N+ membranes (Amersham, Little Chalfont, U.K.). DNA fragments were bound to the membrane by baking in an oven $\left(\right.$ at $84^{\circ} \mathrm{C}$ ) for $2 \mathrm{~h}$. The probe was produced by a PCR reaction using the plasmid pART-IR$\mathrm{HC}$ (Fig. 1) as a template and the primers used for the transgene construct. The amplified PCR fragment (657 nt) was purified using the Product Purification Kit (Bioneer, Seoul, Korea) and labeled with $[\alpha-32 \mathrm{P}] \mathrm{dCTP}$ using a randomly primed ${ }^{32} \mathrm{P}$-labeled DNA probe (Klenow fragment; Fermentas Life Sciences, Vilnius, Lithuania). The membranes were hybridized at $65^{\circ} \mathrm{C}$ for $16 \mathrm{~h}$ and washed twice for $20 \mathrm{~min}$. They were washed first with $1 \times \mathrm{SSC}(1 \times \mathrm{SSC}$ is $0.15 \mathrm{M} \mathrm{NaCl}$ plus $0.015 \mathrm{M}$ sodium citrate), $0.1 \%$ sodium dodecyl sulfate (SDS) at room temperature and then with $0.1 \times \mathrm{SSC}, 0.1 \% \mathrm{SDS}$ at $65^{\circ} \mathrm{C}$. The hybridized membrane was placed on a Fuji Image Plate overnight and then read using a phosphorimager (Fujifilm FLA-5100, Fuji Photo Film Co., Tokyo).

RNA extraction, RT-PCR, and Northern blotting analysis.

The expression of the transgenic RNA was evaluated using RT-PCR and by Northern blotting of t-siRNA. Total RNA was extracted from seedling leaves (second or third youngest) 3 weeks after germination with the TRI-Reagent kit (Molecular Research Center, Inc., Cincinnati, OH, U.S.A.). RT-PCR was conducted in two steps: cDNA synthesis using the Verso cDNA Kit (Thermo Fisher Scientific, Epsom, U.K.) with transgenespecific P1-sense primer, followed by PCR amplification using DreamTaq Green PCR Master Mix (Fermentas Life Sciences) with additional P2-antisense primer. PCR conditions were as described for the analysis of the transgene DNA. For detection of t-siRNA, total RNA $(10 \mu \mathrm{g})$ in $50 \%$ formamide was loaded into each lane of a $15 \%$ acrylamide $8 \mathrm{M}$ urea gel buffered in $100 \mathrm{mM}$ 3-[N-morpholino]propanesulfonic acid (MOPS), $\mathrm{pH}$ 7. Electrophoresis was carried out in $20 \mathrm{mM}$ MOPS buffer and the material was electrotransferred in water (Bio-Rad semidry; Bio-Rad, Hercules, CA, U.S.A.) to a Amersham Hybond NX (GE) nylon membrane (Amersham, Little Chalfont, U.K.) at $20 \mathrm{~V}$ for $45 \mathrm{~min}$. RNA was cross-linked to the membranes with 1-ethyl-3-(3-dimethylaminopropyl) carbodiimide (Pall et al. 2007). The labeled probe for the detection of t-siRNA was a mixture of three DNA primers based on the transgene sequence peaks (5'-GGGTTCCATCATCCATCGTTA-3', 5'-AAT GCCTCCTCACCAGTCAGA-3', and 5'-GCCTTCTATGTGA CAACCAATT-3'). The DNA primers were end labeled with $\left[\gamma-{ }^{32} \mathrm{P}\right] \mathrm{dATP}$ and T4 polynucleotide kinase (New England Biolabs, Ipswich, MA, U.S.A.). Detection of miRNA and hybridization conditions were as reported by Shiboleth and associates (2007).

\section{Deep sequencing and small-RNA analysis.}

Total RNA was extracted from three plants per treatment using TRI-Reagent. We used four leaf discs per plant per sample, which were taken from the second and third leaves of transgenic cucumber lines 823 and 887 and melon 443 and 177 lines (with three to four true leaves) harvested 10 to 14 days after germination. Similar samples were collected from nontransgenic cucumber Ilan and melon 'Arava' plants that had been infected with ZYMV 7 dpi. Duplicate libraries were constructed from independent RNA samples. Deep sequencing was performed on an Illumina Solexa platform using the manufacturer's standard protocol: $20 \mu \mathrm{l}$ RNA was precipitated in three volumes of ethanol with a $10 \%$ solution of $3 \mathrm{M}$ $\mathrm{NaOAc}$ by the Iowa State University DNA Facility (Ames, IA, U.S.A.).

\section{Data mining the small-RNA pool.}

t-siRNA and vsiRNA libraries of 21 to 24 nt were constructed by Genotypic Technology, Bangalore, India. The small-RNA sequences were mapped to the 657-nt region of the ZYMV HC-Pro genome and the data analysis was performed using the CLC Main Workbench program (Katrinebjerg, Denmark).

\section{Evaluation of virus resistance.}

Transgenic seedlings were screened for resistance to three Potyvirus spp. (ZYMV, PRSV-W, and WMV) and CMV following mechanical inoculation. Inoculated seedlings were kept in a greenhouse for several weeks. The responses of the transgenic lines to inoculation were determined by visual monitoring of symptoms for 45 days. We also used RT-PCR to test for the presence of viral RNA 3 to 4 weeks postinoculation. An additional analysis of resistance involved mechanical back inoculation to control squash plants. RT-PCR analyses of virus accumulation were performed in two steps, as described above. Specific primers were used for each virus: $3^{\prime}$ genome of ZYMV (5'-AGCTCCATACATAGCTGAGACA-3' and 5'-GA ACCAAGAGGCGAATTGCT-3'), HC-Pro gene of PRSV-W (5'-ATGGATGTCGCTGAGAAGTTCTGGCTCGG-3' and 5'GCCAACTCTGTAATGTTTCATCTC-3'), CP gene of WMV (5'-GGACTCGAAGAAGGACACCA-3' and 5'-CCGTCCATC ATTACCCAAAC-3'), and RNA3 of CMV-Fny (5'-CTGATCT GGGCGACAAGGA-3' and 5'-CGATAACGACAGCAAAAC AC- $\left.3^{\prime}\right)$.

\section{Q-PCR for the evaluation \\ of virus accumulation and endogenous gene expression.}

Q-RT-PCR was used to evaluate the accumulation of PRSV$\mathrm{W}$ and WMV in transgenic cucumber lines 823 and 887. RNA was extracted from the second youngest leaf of inoculated plants at $14 \mathrm{dpi}$. The concentration and integrity of the RNA samples were determined using an ND1000 spectrophotometer (NanoDrop products; Thermo Scientific, Wilmington, DE, U.S.A.) and by gel analysis, respectively. First-strand cDNA was synthesized from $1 \mu \mathrm{g}$ of total RNA using the Superscript II first-strand synthesis RT-PCR kit (Invitrogen, Carlsbad, CA, U.S.A.) with a specific PRSV reverse primer, according to the manufacturer's instructions. The sequences of the primers used were PRSV-W forward 5'-GAATGGTACATCACCGGA CATA-3' and PRSV-W reverse 5'-CGGAGTGGCATGCTCT ATTA-3'. Cyclophilin cDNA was used as a control reference (accession number AY942800), with forward primer 5'-GTT GCTTTAAGGACTCCGCCA-3' and reverse primer 5'-AGGG GTACCTCCGCATAGCTAG-3'. PCR was performed in a volume of $15 \mu \mathrm{l}$ with $4 \mu \mathrm{l}$ of diluted cDNA (1/4), 3 pmol of each primer, and $7.5 \mu \mathrm{l}$ of Absolute QPCR SYBR Green Mix (Thermo Scientific).

Quantitative analysis was performed using the Rotor-Gene 3000 (Qiagen, Germantown, MD, U.S.A.) with PCR conditions of $20 \mathrm{~min}$ at $95^{\circ} \mathrm{C}$ (hot start) followed by 40 cycles of 15 $\mathrm{s}$ at $96^{\circ} \mathrm{C}, 15 \mathrm{~s}$ at $60^{\circ} \mathrm{C}$, and $15 \mathrm{~s}$ at $72^{\circ} \mathrm{C}$. Three technical replicates of each biological sample were analyzed. The relative level of virus accumulation was calculated using the $\Delta \Delta$ cycle threshold method normalized to cyclophilin as a reference gene using Rotor Gene Series 3000 software version 1.7. The genes for AGO1 (Csa0043920), RDR1 (Csa016070), RDR6 (Csa005844), and DCL4 (Csa016353) of cucumber and melon 
were partially cloned and sequenced based on the Cucurbit Genomics Database to select specific primers for Q-RT-PCR analysis. Q-RT-PCR was performed for the expression level of the endogenous RDR1, RDR6, DCL4, and AGO1 genes for transgenic and nontransgenic cucumber and melon plants. cDNA synthesis was performed once with Oligo(dT) primer (100 pmol) and Q-RT-PCR reactions and analysis were performed as above. An F-box gene (accession GW881870) was used as a control reference for gene expression in cucumber, as recommended (Migocka and Papierniak 2010). Partial cloning of RDR1, RDR6, and DCL4 and the full-length AGO1 gene was performed in a free-form manner, based on sequence homology with other plant genomes. The primer pairs used for each of the endogenous genes and the housekeeping F-box gene were as follows: AGO1, 5'-CTCATCCTCACCCAGGA GAA-3' and 5'-GGGCTTGAGCACTAACCAAA-3'; RDR1, 5'-CTGCACCCTGGTGATGTTC-3' and 5'-GGATGAGGCCT TGATCCTTT-3'; RDR6, 5'-TACCGCCGAATTAGAGATGC-3' and 5'-CCTGCCACTTCGAGGTCTAC-3'; DCL4, 5'-GCCAA GGGATTCATACCTGA-3' and 5'-ATCGTGATCGAGGGTG TTTC-3'; and F-box, 5'-GGTTCATCTGGTGGTCTT-3' and 5'-CTTTAAACGAACGGTCAGTCC-3'.

\section{Western blot analyses.}

To detect ZYMV, total protein was extracted from three squash seedlings infected with ZYMV mutants. Samples (approximately $70 \mathrm{mg}$; four disks per plant) were collected from the second leaf of ZYMV-infected squash plants. Protein extractions and immunoblotting were performed as described by Kimalov and associates (2004) with a ZYMV anti-CP polyclonal antibody (1:4000). For detection of AGO1 protein accumulation, total protein was extracted from a three-plant pool. Samples of tissue $(100 \mathrm{mg}$ ) from the second-top leaf were ground in $300 \mu \mathrm{l}$ of ESB buffer (Kimalov et al. 2004). Soluble proteins were measured using a Qubit fluorometer (Invitrogen, Carlsbad, CA, U.S.A.).

A $30-\mu \mathrm{l}(420 \mathrm{ng} / \mathrm{ml})$ sample of the mixture was fractionated by SDS-polyacrylamide gel electrophoresis in an $8 \%$ polyacrylamide gel overnight $\left(30 \mathrm{~V}\right.$ at $\left.4^{\circ} \mathrm{C}\right)$ and transferred to a Protran membrane. AGO1 polyclonal antibodies were generated against a synthetic peptide (PDTSSIDRQFQQISIQQE) derived from the squash AGO1 sequence by BioCentra LLC (San Antonio, TX, U.S.A.). Specific anti-sqAGO1 immunoglobulin $\mathrm{G}$ was affinity-purified from $2 \mathrm{ml}$ of antiserum by binding $0.6 \mathrm{mg}$ of peptide (PDTSSIDRQFQQISIQQE-C) on a SulfoLink column (Pierce; Thermo Fisher Scientific, Rockford, IL U.S.A.) through the terminal cysteine residue. Purified antibody was reacted with the membrane at a 1:200 dilution overnight at $4^{\circ} \mathrm{C}$, washed, and reacted with AP-anti-rabbit at a 1:5,000 dilution and then developed with NBT-BCIP, in accordance with the manufacturer's instructions (Bio-Rad).

\section{Construction of ZYMV mutants.}

ZYMV mutants harboring nucleotide changes at the corresponding t-siRNA peaks (P1 to P7) were constructed by overlapping PCR. Two complementary primers containing nucleotide mutations were used for each overlapping ZYMV mutant. Two PCR reactions were carried out using ZYMV cDNA (accession number EF062582) as a template. The first PCR used ZYMV forward BstEII primer (position 880 in the ZYMV genome) 5'-AGGTCACCCATACAG AGCAAATT TGTG AGG AAGATATCAAACC-3' and a reverse mutant primer (P-Rev, shown in the list below). The second PCR used reverse ZYMV BamHI primer (position 2,280) 5'-CAAGGATCCGCGGTAA TTCAGCGCATCG-3' and a forward mutant primer (P-Fwd, shown below). A sample of approximately $50 \mathrm{ng}$ of cDNA from each PCR reaction was mixed for annealing and subjected to a third PCR with ZYMV-BstEII forward primer and ZYMVBamHI reverse primer to combine the two fragments. The mutated cDNA fragment replaced was inserted in the infectious ZYMV cDNA in place of the corresponding BstEII/BamHI fragment (Gal-On et al. 1995). Each mutant contained six to seven silent mutations within the 21-nt region corresponding to an siRNA peak (P2, P3, P4, P5, and P7).

The following forward (Fwd) and reverse (Rev) primers were used to construct ZYMV mutants (lowercase letters indicate nucleotide mutations): peak 2 (P2) Fwd (position 1,575 to 1,614) 5'-TCTcACaGGgGAaGAaGCccTGAAAAT GTTCAT AAATAAG-3'; peak 2 (P2) Rev (position 1,556 to 1,595 ) 5' AggGCtTCtTCcCCtGTgAGATGCATG TGGTTCTTAAACC3'; peak 3 (P3) Fwd (position 1,643 to 1,682) 5'-GtCTgCT cTGcGAtAAtCAgTTGGACAAAAATGGAAATTT-3'; peak 3 (P3) Rev (position 1625-1664) 5'-AAcTGaTTaTCgCAgAGcA GaCTAGGATTTATCA TGGCCT-3'; peak 4 (P4) Fwd (position 2,129 to 2,168 ) 5'-TgAAcGAaAAtGAgGCcAAaGATTT CACC AAAATGATT CG-3'; peak 4 (P4) Rev (position 2,110 to 2,149) 5'-CtTTgGCcTCaTTt TCgTTcACATTCACAAG CATTGCGAG-3'; peak 5 (P5) Fwd (position 2,029 to 2,068) 5'-CCcAAaTAtATcGAcCTtCCcGCATCTGAGGCAGAACGC A-3'; peak 5 (P5) Rev (position 2,010 to 2,049) 5'-gGGaAG gTCgATaTAtTTgGGATCACCAGAAGCTCCTATA-3'; peak 7 (P7) Fwd (position 2,053 to 2,092) 5'-TCgGAaGCcGAgCGa ATGTAcATAGC AAAAGAAGGTTATT-3'; peak 7 (P7) Rev (position 2,035 to 2,074) 5'-TgTACATtCGcT CgGCtTCcGAT GCTGGCAGATCAATGTA-3'; nP Fwd (position 1,857 to 1,896) 5'-ACTtCTaGGtGAaAGcATaGAaAAaAAGCCACTC ACATCA-3'; and nP Rev (position 1,842 to 1,881 ) 5'-tTTtT CtATgCTtTCaCCtAGaAGTGCAGTGCGTGCCCTA-3' .

Three additional infectious clones were constructed, one with mutations in all peaks ( $\mathrm{P} 2, \mathrm{P} 3, \mathrm{P} 4, \mathrm{P} 5$, and $\mathrm{P} 7)$ and two others with nucleotide changes every 10 or $6 \mathrm{nt}$ throughout the transgene region. These clones were made by replacing wildtype sequences with synthetic fragments containing the multiple nucleotide changes. Synthetic fragments made by Geneart (Regensburg, Germany) that contained unique restriction sites for NsiI (position 1,575) or HindIII (position 1,250) at the $5^{\prime}$ end and BamHI $(2,280)$ at the $3^{\prime}$ end were cloned into the appropriate site within the ZYMV infection clone (Gal-On et al. 1995).

\section{AKNOWLEDGMENTS}

Contribution from the Agricultural Research Organization, The Volcani Center, Bet Dagan, Israel, number 504/11. This work was supported in part by grants from the Chief Scientist's Office, Ministry of Agriculture, and the United States-Israel Binational Agricultural Research and Development Fund (BARD) (grant USA 3623-04).

\section{LITERATURE CITED}

Alamillo, J. M., Saenz, P., and Garcia, J. A. 2006. Salicylic acid-mediated and RNA-silencing defense mechanisms cooperate in the restriction of systemic spread of Plum pox virus in tobacco. Plant J. 48:217-227.

Aliyari, R., and Ding, S. W. 2009. RNA-based viral immunity initiated by the Dicer family of host immune receptors. Immunol. Rev. 227:176-188.

Baulcombe, D. 2004. RNA silencing in plants. Nature 431:356-363.

Bouche, N., Lauressergues, D., Gasciolli, V., and Vaucheret, H. 2006. An antagonistic function for Arabidopsis DCL2 in development and a new function for DCL4 in generating viral siRNAs. EMBO (Eur. Mol. Biol. Organ.) J. 25:3347-3356.

Boutet, S., Vazquez, F., Liu, J., Beclin, C., Fagard, M., Gratias, A., Morel, J. B., Crete, P., Chen, X., and Vaucheret, H. 2003. Arabidopsis HEN1: a genetic link between endogenous miRNA controlling development and siRNA controlling transgene silencing and virus resistance. Curr. Biol. 13:843-848.

Brodersen, P., and Voinnet, O. 2006. The diversity of RNA silencing pathways in plants. Trends Genet. 22:268-280. 
Brodersen, P., and Voinnet, O. 2009. Revisiting the principles of microRNA target recognition and mode of action. Nat. Rev. Mol. Cell Biol. 10:141-148.

Bucher, E., Lohuis, D., van Poppel, P. M., Geerts-Dimitriadou, C., Goldbach, R., and Prins, M. 2006. Multiple virus resistance at a high frequency using a single transgene construct. J. Gen. Virol. 87:36973701

Bucher, E., Lohuis, D., van Poppel, P. M., Geerts-Dimitriadou, C. Goldbach, R., and Prins, M. 2006. Multiple virus resistance at a high frequency using a single transgene construct. J. Gen. Virol. 87:36973701

Chen, Y., Lohuis, D., Goldbach, R., and Prins, M. 2004. High frequency induction of RNA-mediated resistance against Cucumber mosaic virus using inverted repeat constructs. Mol. Breed. 14:215-226.

Cuperus, J. T., Carbonell, A., Fahlgren, N., Garcia-Ruiz, H., Burke, R. T., Takeda, A., Sullivan, C. M., Gilbert, S. D., Montgomery, T. A., and Carrington, J. C. 2010. Unique functionality of 22-nt miRNAs in triggering RDR6-dependent siRNA biogenesis from target transcripts in Arabidopsis. Nat. Struct. Mol. Biol. 17:997-1003.

Dalmay, T., Horsefield, R., Braunstein, T. H., and Baulcombe, D. C. 2001 SDE3 encodes an RNA helicase required for post-transcriptional gene silencing in Arabidopsis. EMBO (Eur. Mol. Biol. Organ.) J. 20:20692078.

Deleris, A., Gallego-Bartolome, J., Bao, J., Kasschau, K. D., Carrington, J. C., and Voinnet, O. 2006. Hierarchical action and inhibition of plant Dicer-like proteins in antiviral defense. Science 313:68-71.

Dellaporta, S. L., Wood, J., and Hicks, J. B. 1983. A plant DNA minipreparation version II. Plant Mol. Biol. Rep. 1:19-21.

Ding, S. W. 2010. RNA-based antiviral immunity. Nat. Rev. Immunol 10:632-644

Ding, S. W., and Voinnet, O. 2007. Antiviral immunity directed by small RNAs. Cell 130:413-426.

Donaire, L., Barajas, D., Martínez-García, B., Martínez-Priego, L., Pagán, I., and Llave, C. 2008. Structural and genetic requirements for the biogenesis of tobacco rattle virus-derived small interfering RNAs. J Virol. 82:5167-177.

Donaire, L., Wang, Y., Gonzalez-Ibeas, D., Mayer, K. F., Aranda, M. A., and Llave, C. 2009. Deep-sequencing of plant viral small RNAs reveals effective and widespread targeting of viral genomes. Virology 392:203214

Duan, C. G., Wang, C. H., Fang, R. X., and Guo, H. S. 2008. Artificial MicroRNAs highly accessible to targets confer efficient virus resistance in plants. J. Virol. 82:11084-11095.

Dunoyer, P., Brosnan, C. A., Schott, G., Wang, Y., Jay, F., Alioua, A., Himber, C., and Voinnet, O. 2010a. An endogenous, systemic RNAi pathway in plants. EMBO (Eur. Mol. Biol. Organ.) J. 29:1699-1712.

Dunoyer, P., Schott, G., Himber, C., Meyer, D., Takeda, A., Carrington, J. C., and Voinnet, O. 2010b. Small RNA duplexes function as mobile silencing signals between plant cells. Science 328:912-916.

Eamens, A., Wang, M. B., Smith, N. A., and Waterhouse, P. M. 2008. RNA silencing in plants: yesterday, today, and tomorrow. Plant Physiol. 147:456-468

Fuchs, M., and Gonsalves, D. 1995. Resistance of transgenic hybrid squash Zw-20 expressing the coat protein genes of Zucchini yellow mosaic virus and Watermelon mosaic virus-2 to mixed Infections by both potyviruses. BioTechnology 13:1466-1473.

Fusaro, A. F., Matthew, L., Smith, N. A., Curtin, S. J., Dedic-Hagan, J., Ellacott, G. A., Watson, J. M., Wang, M. B., Brosnan, C., Carroll, B. J., and Waterhouse, P. M. 2006. RNA interference-inducing hairpin RNAs in plants act through the viral defence pathway. EMBO (Eur. Mol. Biol. Organ.) Rep. 7:1168-1175.

Gaba, V., Rosner, A., Maslenin, L., Leibman, D., Singer, S., Kukurt, E., Shiboleth, Y. M., and Gal-On, A. 2010. Hairpin-based virus resistance depends on the sequence similarity between challenge virus and discrete, highly accumulating siRNA species. Eur. J. Plant Pathol. 128:153-164.

Gal-On, A. 2007. Zucchini yellow mosaic virus: insect transmission and pathogenicity - the tails of two proteins. Mol. Plant Pathol. 8:139-150.

Gal-On, A., and Raccah, B. 2000. A point mutation in the FRNK motif of the Potyvirus HC-Pro gene alters symptom expression in cucurbits and elicits protection against the severe homologous virus. Phytopathology 90:467-473.

Gal-On, A., Antignus, Y., Rosner, A., and Raccah, B. 1991. Infectious in vitro RNA transcripts derived from cloned cDNA of the cucurbit potyvirus, zucchini yellow mosaic virus. J. Gen. Virol. 72:2639-2643.

Gal-On, A., Meiri, E., Huet, H., Hua, W. J., Raccah, B., and Gaba, V. 1995. Particle bombardment drastically increases the infectivity of cloned DNA of zucchini yellow mosaic potyvirus. J. Gen. Virol. 76:3223-3227.

Gal-On, A., Wolf, D., Antignus, Y., Patlis, L., Ryu, K. H., Min, B. E., Pearlsman, M., Lachman, O., Gaba, V., Wang, Y., Shiboleth, Y. M.,
Yang, J., and Zelcer, A. 2005. Transgenic cucumbers harboring the 54$\mathrm{kDa}$ putative gene of Cucumber fruit mottle mosaic tobamovirus are highly resistant to viral infection and protect non-transgenic scions from soil infection. Transgenic Res. 14:81-93.

Garcia-Ruiz, H., Takeda, A., Chapman, E. J., Sullivan, C. M., Fahlgren, N., Brempelis, K. J., and Carrington, J. C. 2010. Arabidopsis RNA-dependent RNA polymerases and dicer-like proteins in antiviral defense and small interfering RNA biogenesis during Turnip mosaic virus infection. Plant Cell 22:481-496.

Glazov, E., Phillips, K., Budziszewski, G. J., Schob, H., Meins, F., Jr., and Levin, J. Z. 2003. A gene encoding an RNase D exonuclease-like protein is required for post-transcriptional silencing in Arabidopsis. Plant J. 35:342-349.

Ho, T., Wang, H., Pallett, D., and Dalmay, T. 2007. Evidence for targeting common siRNA hotspots and GC preference by plant Dicer-like proteins. FEBS (Fed. Eur. Biochem. Soc.) Lett. 581:3267-3272.

Ho, T., Wang, L., Huang, L., Li, Z., Pallett, D. W., Dalmay, T., Ohshima, K., Walsh, J. A., and Wang, H. 2010. Nucleotide bias of DCL and AGO in plant anti-virus gene silencing. Protein Cell 1:847-858.

Ji, L. H., and Ding, S. W. 2001. The suppressor of transgene RNA silencing encoded by Cucumber mosaic virus interferes with salicylic acidmediated virus resistance. Mol. Plant-Microbe Interact. 14:715-724.

Kalantidis, K., Psaradakis, S., Tabler, M., and Tsagris, M. 2002. The occurrence of CMV-specific short RNAs in transgenic tobacco expressing virus-derived double-stranded RNA is indicative of resistance to the virus. Mol. Plant-Microbe Interact. 15:826-833.

Kimalov, B., Gal-On, A., Stav, R., Belausov, E., and Arazi, T. 2004. Maintenance of coat protein $\mathrm{N}$-terminal net charge and not primary sequence is essential for Zucchini yellow mosaic virus systemic infectivity. J. Gen. Virol. 85:3421-3430.

Kreuze, J. F., Klein, I. S., Lazaro, M. U., Chuquiyuri, W. J., Morgan, G. L., Mejia, P. G., Ghislain, M., and Valkonen, J. P. 2008. RNA silencing-mediated resistance to a crinivirus (Closteroviridae) in cultivated sweet potato (Ipomoea batatas L.) and development of sweet potato virus disease following co-infection with a potyvirus. Mol. Plant Pathol. 9:589598.

Li, J., Yang, Z., Yu, B., Liu, J., and Chen, X. 2005. Methylation protects miRNAs and siRNAs from a 3'-end uridylation activity in Arabidopsis. Curr. Biol. 15:1501-1507.

Lindbo, J. A., and Dougherty, W. G. 2005. Plant pathology and RNAi: a brief history. Annu. Rev. Phytopathol. 43:191-204.

Lindbo, J. A., Silva-Rosales, L., Proebsting, W. M., and Dougherty, W. G. 1993. Induction of a highly specific antiviral state in transgenic plants: implications for regulation of gene expression and virus resistance. Plant Cell 5:1749-1759.

Llave, C. 2010. Virus-derived small interfering RNAs at the core of plantvirus interactions. Trends Plant Sci. 15:701-707.

Lopez, C., Cervera, M., Fagoaga, C., Moreno, P., Navarro, L., Flores, R. and Pena, L. 2010. Accumulation of transgene-derived siRNAs is not sufficient for RNAi-mediated protection against Citrus tristeza virus in transgenic Mexican lime. Mol. Plant Pathol. 11:33-41.

Lozsa, R., Csorba, T., Lakatos, L., and Burgyan, J. 2008. Inhibition of 3 modification of small RNAs in virus-infected plants require spatial and temporal co-expression of small RNAs and viral silencing-suppressor proteins. Nucleic Acids Res. 36:4099-4107.

Mi, S., Cai, T., Hu, Y., Chen, Y., Hodges, E., Ni, F., Wu, L., Li, S., Zhou, H., Long, C., Chen, S., Hannon, G. J., and Qi, Y. 2008. Sorting of small RNAs into Arabidopsis argonaute complexes is directed by the $5^{\prime}$ terminal nucleotide. Cell 133:116-127.

Migocka, M., and Papierniak, A. 2010. Identification of suitable reference genes for studying gene expression in cucumber plants subjected to abiotic stress and growth regulators. Mol. Breed. Online publication. doi:10.1007/s11032-010-9487-0

Missiou, A., Kalantidis, K., Boutla, A., Tzortzakaki, S., Tabler, M., and Tsagris, M. 2004. Generation of transgenic potato plants highly resistant to potato virus $Y$ (PVY) through RNA silencing. Mol. Breed. 14:185-197.

Molnar, A., Csorba, T., Lakatos, L., Varallyay, E., Lacomme, C., and Burgyan, J. 2005. Plant virus-derived small interfering RNAs originate predominantly from highly structured single-stranded viral RNAs. J. Virol. 79:7812-7818.

Molnar, A., Melnyk, C. W., Bassett, A., Hardcastle, T. J., Dunn, R., and Baulcombe, D. C. 2010. Small silencing RNAs in plants are mobile and direct epigenetic modification in recipient cells. Science 328:872-875

Mourrain, P., Beclin, C., Elmayan, T., Feuerbach, F., Godon, C., Morel, J. B., Jouette, D., Lacombe, A. M., Nikic, S., Picault, N., Remoue, K., Sanial, M., Vo, T. A., and Vaucheret, H. 2000. Arabidopsis SGS2 and SGS3 genes are required for posttranscriptional gene silencing and natural virus resistance. Cell 101:533-542.

Murray, M. G., and Thompson, W. F. 1980. Rapid isolation of high molecular weight plant DNA. Nucleic Acids Res. 8:4321-4325. 
Niu, Q. W., Lin, S. S., Reyes, J. L., Chen, K. C., Wu, H. W., Yeh, S. D., and Chua, N. H. 2006. Expression of artificial microRNAs in transgenic Arabidopsis thaliana confers virus resistance. Nat. Biotechnol. 24:1420-1428.

Palatnik, J. F., Wollmann, H., Schommer, C., Schwab, R., Boisbouvier, J., Rodriguez, R., Warthmann, N., Allen, E., Dezulian, T., Huson, D., Carrington, J. C., and Weigel, D. 2007. Sequence and expression differences underlie functional specialization of Arabidopsis microRNAs miR159 and miR319. Dev. Cell 13:115-125.

Pall, G. S., Codony-Servat, C., Byrne, J., Ritchie, L., and Hamilton, A. 2007. Carbodiimide-mediated cross-linking of RNA to nylon membranes improves the detection of siRNA, miRNA and piRNA by Northern blot. Nucleic Acids Res. 35:e60.

Patil, B. L., Ogwok, E., Wagaba, H., Mohammed, I. U., Yadav, J. S., Bagewadi, B., Taylor, N. J., Kreuze, J. F., Maruthi, M. N., Alicai, T., and Fauquet, C. M. 2011. RNAi-mediated resistance to diverse isolates belonging to two virus species involved in Cassava brown streak disease. Mol. Plant Pathol. 12:31-41.

Prins, M., Laimer, M., Noris, E., Schubert, J., Wassenegger, M., and Tepfer, M. 2008. Strategies for antiviral resistance in transgenic plants. Mol. Plant. Pathol. 9:73-83.

Qi, X., Bao, F. S., and Xie, Z. 2009. Small RNA deep sequencing reveals role for Arabidopsis thaliana RNA-dependent RNA polymerases in viral siRNA biogenesis. PLoS One 4:e4971.

Qu, F. 2010. Antiviral role of plant-encoded RNA-dependent RNA polymerases revisited with deep sequencing of small interfering RNAs of virus origin. Mol. Plant-Microbe Interact. 23:1248-1252.

Qu, J., Ye, J., and Fang, R. 2007. Artificial microRNA-mediated virus resistance in plants. J. Virol. 81:6690-6699.

Rakhshandehroo, F., Takeshita, M., Squires, J., and Palukaitis, P. 2009. The influence of RNA-dependent RNA polymerase 1 on Potato virus $Y$ infection and on other antiviral response genes. Mol. Plant-Microbe Interact. 22:1312-1318.

Rizzo, T. M., and Palukaitis, P. 1990. Construction of full-length cDNA clones of cucumber mosaic virus RNAs 1, 2 and 3: generation of infectious RNA transcripts. Mol. Gen. Genet. 222:249-256.

Ruiz-Ferrer, V., and Voinnet, O. 2009. Roles of plant small RNAs in biotic stress responses. Annu. Rev. Plant Biol. 60:485-510.

Savenkov, E. I., and Valkonen, J. P. 2002. Silencing of a viral RNA silencing suppressor in transgenic plants. J. Gen. Virol. 83:2325-2335.

Shiboleth, Y. M., Haronsky, E., Leibman, D., Arazi, T., Wassenegger, M., Whitham, S. A., Gaba, V., and Gal-On, A. 2007. The conserved FRNK box in HC-Pro, a plant viral suppressor of gene silencing, is required for small RNA binding and mediates symptom development. J. Virol. $81: 13135-13148$

Vanderschuren, H., Alder, A., Zhang, P., and Gruissem, W. 2009. Dosedependent RNAi-mediated geminivirus resistance in the tropical root crop cassava. Plant Mol. Biol. 70:265-272.
Varallyay, E., Valoczi, A., Agyi, A., Burgyan, J., and Havelda, Z. 2010. Plant virus-mediated induction of miR168 is associated with repression of ARGONAUTE1 accumulation. EMBO (Eur. Mol. Biol. Organ.) J. 29:3507-3519.

Vaucheret, H., Vazquez, F., Crete, P., and Bartel, D. P. 2004. The action of ARGONAUTE1 in the miRNA pathway and its regulation by the miRNA pathway are crucial for plant development. Genes Dev. 18:1187-1197.

Wang, X. B., Wu, Q., Ito, T., Cillo, F., Li, W. X., Chen, X., Yu, J. L., and Ding, S. W. 2010. RNAi-mediated viral immunity requires amplification of virus-derived siRNAs in Arabidopsis thaliana. Proc. Natl. Acad. Sci. U.S.A. 107:484-489.

Waterhouse, P. M., Graham, M. W., and Wang, M. B. 1998. Virus resistance and gene silencing in plants can be induced by simultaneous expression of sense and antisense RNA. Proc. Natl. Acad. Sci. U.S.A. 95:13959-13964.

Waterhouse, P. M., Wang, M. B., and Lough, T. 2001. Gene silencing as an adaptive defence against viruses. Nature 411:834-842.

Wesley, S. V., Helliwell, C. A., Smith, N. A., Wang, M. B., Rouse, D. T. Liu, Q., Gooding, P. S., Singh, S. P., Abbott, D., Stoutjesdijk, P. A., Robinson, S. P., Gleave, A. P., Green, A. G., and Waterhouse, P. M 2001. Construct design for efficient, effective and high-throughput gene silencing in plants. Plant J. 27:581-590.

Wu, H. W., Yu, T. A., Raja, J. A., Wang, H. C., and Yeh, S. D. 2009. Generation of transgenic oriental melon resistant to Zucchini yellow mosaic virus by an improved cotyledon-cutting method. Plant Cell Rep. 28:1053-1064

Xie, Z., Fan, B., Chen, C., and Chen, Z. 2001. An important role of an inducible RNA-dependent RNA polymerase in plant antiviral defense. Proc. Natl. Acad. Sci. U.S.A. 98:6516-6521.

Xie, Z., Johansen, L. K., Gustafson, A. M., Kasschau, K. D., Lellis, A. D. Zilberman, D., Jacobsen, S. E., and Carrington, J. C. 2004. Genetic and functional diversification of small RNA pathways in plants. PLoS Biol. 2:E104.

Yu, D., Fan, B., MacFarlane, S. A., and Chen, Z. 2003. Analysis of the involvement of an inducible Arabidopsis RNA-dependent RNA polymerase in antiviral defense. Mol. Plant-Microbe Interact. 16:206-216.

Yu, T. A., Chiang, C. H., Wu, H. W., Li, C. M., Yang, C. F., Chen, J. H. Chen, Y. W., and Yeh, S. D. 2010. Generation of transgenic watermelon resistant to Zucchini yellow mosaic virus and Papaya ringspot virus type W. Plant Cell Rep. 30:359-371.

\section{AUTHOR-RECOMMENDED INTERNET RESOURCES}

The Samuel Roberts Noble Foundation prediction server: bioinfo3.noble.org/psRNATarget/index.php?function=function3 CLC Bioinformatics Main Workbench program: www.clcbio.com Cucurbit Genomics database: www.icugi.org 